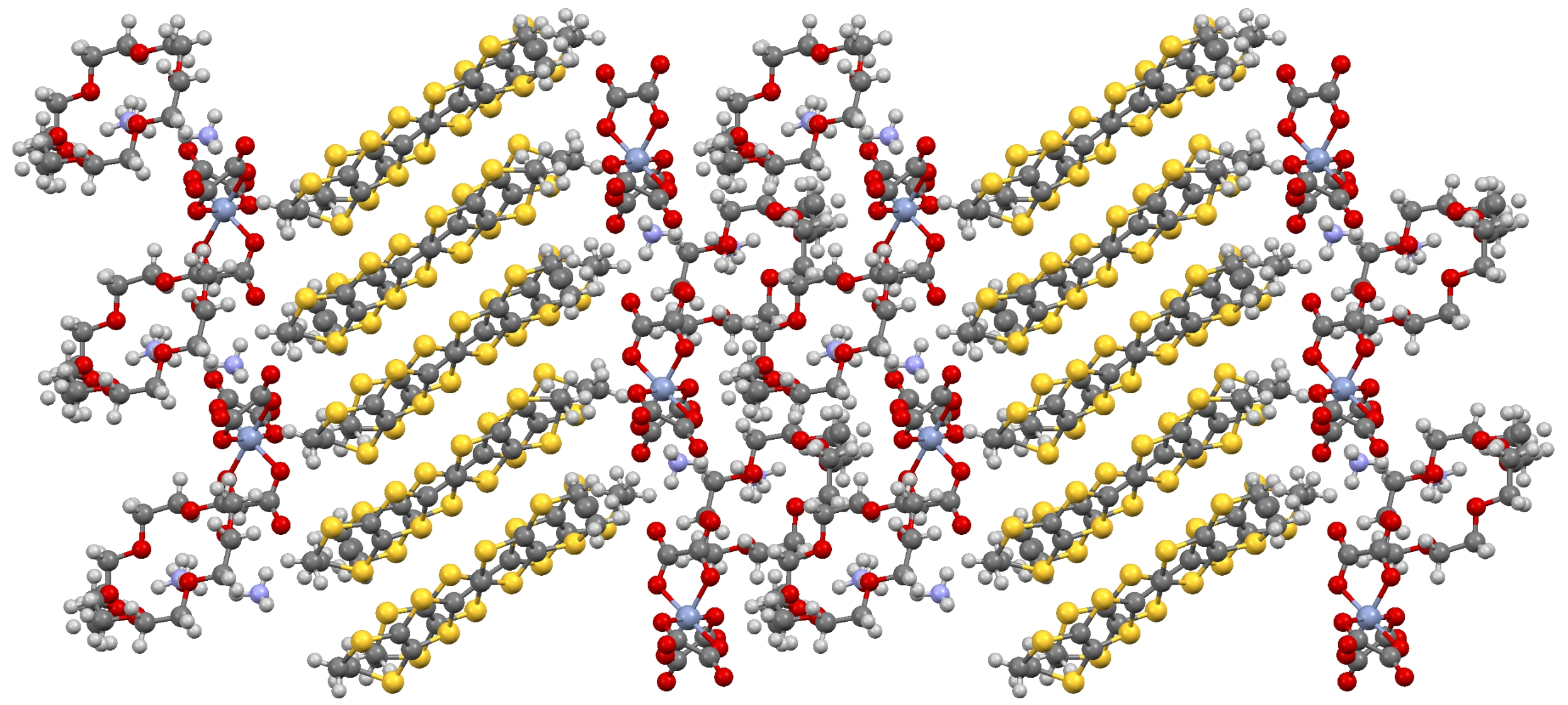




\title{
Molecular conductors of BEDT-TTF with tris(oxalato)metallate anions
}

\author{
Lee Martin ${ }^{\mathrm{a}, *}$ \\ aSchool of Science and Technology, Nottingham Trent University, Clifton Lane, Nottingham, NG11 8NS, \\ UK. \\ Corresponding author: E-mail: lee.martin@ntu.ac.uk
}

\section{ABSTRACT}

This review presents the synthesis, crystal structures and conducting properties of BEDT-TTF radicalcation salts with the tris(oxalato)metallate anion [BEDT-TTF = bis(ethylenedithio)tetrathiafulvalene]. This series has received much attention owing to the wide variety of conducting properties that have been observed. As well as including numerous metals, semiconductors and insulators, there are over twenty superconductors in this series. The series also includes several examples of multifunctionality where it has been possible to combine together particular physical properties in the same lattice such as electrical conductivity with magnetism, chirality or proton conductivity. This review presents an overview of the flexibility of the coordination chemistry of the oxalate ligand and the variety of packing arrangements of the tris(oxalato)metallate complexes in the insulating layers of these radical-cation salts.

\section{INTRODUCTION}

Since the discovery of the first metallic charge-transfer salt of TTF-TCNQ in 1973 [1] extensive research has been performed in the field of molecular conductors with TTF derivatives. Studies of these 1dimensional and 2-dimensional (1D and 2D) molecular conductors have investigated many interesting phenomena such as spin-Pieirls, charge order, Mott insulators, quantum spin-liquids, and spin density waves.[2] Organic superconductivity was first observed in a radical-cation salt of TMTSF (tetramethyltetraselenafulvalene) with the $\mathrm{PF}_{6}-$ anion.[3] The majority of organic superconductors have been found with the donor molecule BEDT-TTF (Scheme 1), with к-(BEDT-TTF) ${ }_{2} \mathrm{Cu}\left[\mathrm{N}(\mathrm{CN})_{2}\right] \mathrm{Br}$ showing the highest Tc at ambient pressure, $11.6 \mathrm{~K}$, whilst $\mathrm{K}-(\mathrm{BEDT}-\mathrm{TTF})_{2} \mathrm{Cu}\left[\mathrm{N}(\mathrm{CN})_{2}\right] \mathrm{Cl}$ has a Tc of $13.1 \mathrm{~K}$ under applied pressure, and $\beta^{\prime}$-(BEDT-TTF) ${ }_{2} \mathrm{ICl}_{2}$ has the highest Tc under applied pressure of $14.2 \mathrm{~K}[4]$ Transition-metal complexes have been extensively used in radical-cation salts of BEDT-TTF because they offer the possibility of combining two or more properties in the same lattice. The most extensive family of these salts employs the tris(oxalato)metallate anion to combine conductivity with paramagnetism,[5] ferromagnetism,[6] or anti-ferromagnetism.[7] The ability of the tris(oxalato)metallate anion $\left[\mathrm{M}\left(\mathrm{C}_{2} \mathrm{O}_{4}\right)_{3}\right]^{3-}$ to form infinite $2 \mathrm{D}$ sheets in a hexagonal network offers many possibilities for making subtle changes to the crystal structure, such as changing the metal centre, the counter cation, or the guest solvent molecule which is located within the hexagonal cavities of the 2D sheet. These small changes can have a drastic effect upon the crystal structure and thus the physical properties of the material. The bridging capability of the oxalato ligand has also made it possible to introduce two different metal centres into the same layer leading to long-range magnetic order. This review will focus on the molecular superconductors, metals, semiconductors and insulators derived from BEDT-TTF with tris(oxalato)metallate anions.

\section{4:1 radical cation-salts of BEDT-TTF with tris(oxalato)metallate(III)}

Research into magnetic molecule-based materials that also exhibit conductivity by the group of Prof. Peter Day at the Royal Institution of Great Britain led to the discovery in 1995 of the first molecular paramagnetic superconductor in the radical-cation salt $\beta^{\prime \prime}-(\mathrm{BEDT}-\mathrm{TTF})_{4}\left[\left(\mathrm{H}_{3} \mathrm{O}\right) \mathrm{Fe}\left(\mathrm{C}_{2} \mathrm{O}_{4}\right)_{3}\right] \cdot \mathrm{PhCN}$ (Fig. 
1).[5,8-11] This was an important discovery owing to the antagonistic relationship between superconductivity and magnetism. Several studies of the magnetic and electrical properties of this radical-cation salt observed the superconducting transition at $7.0 \mathrm{~K}$ to $8.5 \mathrm{~K}$, which is the highest Tc of all known BEDT-TTF/tris(oxalato)metallate superconductors to date.

\subsection{Monoclinic $\beta$ " superconductors, metals and semiconductors}

$\beta "$-(BEDT-TTF $)_{4}\left[\left(\mathrm{H}_{3} \mathrm{O}\right) \mathrm{Fe}\left(\mathrm{C}_{2} \mathrm{O}_{4}\right)_{3}\right]$.benzonitrile crystallises in the monoclinic space group $\mathrm{C} 2 / \mathrm{c}$. [5,8-11] The asymmetric unit consists of two crystallographically independent BEDT-TTF ${ }^{0.5+}$ molecules, half an $\mathrm{Fe}\left(\mathrm{C}_{2} \mathrm{O}_{4}\right)_{3-}$ anion, half a solvent molecule, and half an $\mathrm{H}_{3} \mathrm{O}^{+}$cation. The BEDT-TTF cations and tris(oxalato)ferrate anions are segregated into alternating layers (Fig. 1) with the donor molecules adopting a $\beta$ " packing arrangement (Fig. 2). The two crystallographically independent BEDT-TTF molecules pack in an AABBAABB sequence within each donor stack. Within each anion layer the tris(oxalato)metallate and the $\mathrm{H}_{3} \mathrm{O}^{+}$cation adopt a hexagonal packing arrangement with the inner oxygens of the oxalato ligand octahedrally coordinated to the metal and the outer oxygens involved in hydrogen bonding with the $\mathrm{H}_{3} \mathrm{O}^{+}$(Fig. 3). The benzonitrile solvent molecule occupies each hexagonal cavity with its $\mathrm{C} \equiv \mathrm{N}$ bond directed towards an Fe metal centre.

Twenty-nine superconductors of the monoclinic $C 2 / c$ type have since been prepared having the same formula, $\beta^{\prime \prime}$-(BEDT-TTF) ${ }_{4}\left[(\mathrm{~A}) \mathrm{M}\left(\mathrm{C}_{2} \mathrm{O}_{4}\right)_{3}\right]$.solvent(s), making these $4: 1$ salts are the most widely studied of all the BEDT-TTF-tris(oxalato)metallate radical-cation salts. Changing the counter cation $(\mathrm{A}=$ $\left.\mathrm{H}_{3} \mathrm{O}^{+} / \mathrm{K}^{+} / \mathrm{NH}_{4}^{+}\right)$and changing the metal centre of the tris(oxalato)metallate $\left(\mathrm{M}=\mathrm{Fe}^{3+}, \mathrm{Cr}^{3+}, \mathrm{Ga}^{3+}, \mathrm{Rh}^{3+}\right.$, $\mathrm{Ru}^{3+}, \mathrm{Mn}^{3+}$ ) has only a very small effect upon the properties (Tables 1 and 2 ). In the benzonitrile salts changing the tris(oxalato)metallate from $\mathrm{Fe}$ to $\mathrm{Cr}$ lead to a reduction of superconducting Tc from 7.0$8.5 \mathrm{~K}$ to $5.5-6.0 \mathrm{~K}$. Much more marked effects upon the physical properties changing from superconductors to metals or semiconductors occurs when changing the size and shape of the guest solvent molecule (Table 1-3). Some of the $\beta$ "-(BEDT-TTF $)_{4}\left[(A) M\left(C_{2} \mathrm{O}_{4}\right)_{3}\right]$.halobenzene salts undergo a phase transition from monoclinic $C 2 / c$ to triclinic $P-1$ at temperatures around 200K.[15,18]

Table 1 shows the variety of conducting properties possible in the $\beta^{\prime \prime}$-(BEDT$\mathrm{TTF})_{4}\left[(\mathrm{~A}) \mathrm{Fe}\left(\mathrm{C}_{2} \mathrm{O}_{4}\right)_{3}\right]$-solvent salts. Highest superconducting Tcs are observed when larger guest solvent molecules are filling the hexagonal cavity, and specifically those which increase the $b$ axis length the most. Benzonitrile is the guest solvent molecule which extend the $b$-axis of the hexagonal cavity the furthest. In the benzonitrile salt there is no BEDT-TTF ethylene disorder, even at room temperature, and superconductivity is observed. In contrast, in the pyridine salt no superconductivity is observed down to $1 \mathrm{~K}$. To investigate this a series of salts were synthesised containing different mole fractions of benzonitrile and pyridine (Table 3 ) and their conducting properties showed a sharp cut-off in the superconductivity at $>65 \%$ concentrations of pyridine. Another study using mixed solvents showed that the Tc of the pure benzonitrile salt could be reduced by the inclusion of increasing amounts of a second solvent.[11,17]

\subsection{Orthorhombic pseudo-k semiconductors}

When using benzonitrile as solvent a $2^{\text {nd }}$ phase is obtained which has the same chemical formula as the superconducting monoclinic $\beta^{\prime \prime}-(\mathrm{BEDT}-\mathrm{TTF})_{4}\left[(\mathrm{~A}) \mathrm{M}\left(\mathrm{C}_{2} \mathrm{O}_{4}\right)_{3}\right] \cdot \mathrm{PhCN}$ but the BEDT-TTF donor molecules pack in a very different manner. Pseudo-K-(BEDT-TTF) $)_{4}\left[\left(\mathrm{~K}\right.\right.$ or $\left.\left.\mathrm{NH}_{4}\right) \mathrm{Fe}\left(\mathrm{C}_{2} \mathrm{O}_{4}\right)_{3}\right] \cdot \mathrm{PhCN}$ crystallises in the orthorhombic space group $\mathrm{Pbcn}$, with two crystallographically independent BEDTTTF molecules, half an $\mathrm{Fe}\left(\mathrm{C}_{2} \mathrm{O}_{4}\right)_{3}{ }^{3-}$ anion, half a benzonitrile molecule and half of an $\mathrm{NH}_{4}{ }^{+}$or $\mathrm{K}^{+}$cation. The pseudo-k BEDT-TTF packing motif is shown in Figure 4 with $\left(B E D T-T_{T F}{ }^{1+}\right)_{2}$ dimers each surrounded by six neutral BEDT-TTF ${ }^{0}$ monomers which leads to semiconducting behaviour (Table 4). 
The anion layer (Fig. 5) contains $\mathrm{Fe}\left(\mathrm{C}_{2} \mathrm{O}_{4}\right)_{3}{ }^{3-}$ and $\mathrm{NH}_{4}{ }^{+}$or $\mathrm{K}^{+}$in a honeycomb packing arrangement with a benzonitrile molecule occupying the hexagonal cavity. The benzonitrile molecule is disordered over two positions with the $-\mathrm{C} \equiv \mathrm{N}$ group directed towards the $\mathrm{NH}_{4}{ }^{+}$or $\mathrm{K}^{+}$anions giving the hexagonal cavity an increased width compared to in the monoclinic $\beta$ " salts to accommodate the disordered positions of the $-\mathrm{C} \equiv \mathrm{N}$ group.

It is interesting to note that crystals of this orthorhombic pseudo-к phase grow only when using benzonitrile as a solvent. This is the case for all $\mathrm{M}\left(\mathrm{C}_{2} \mathrm{O}_{4}\right)_{3}{ }^{3-}$ anions $-\mathrm{M}=\mathrm{Fe}^{3+}, \mathrm{Cr}^{3+}, \mathrm{Al}^{3+}, \mathrm{Co}^{3+}, \mathrm{Ga}^{3+}, \mathrm{Rh}^{3+}$, $\mathrm{Ru}^{3+}, \mathrm{Mn}^{3+}$ (Table 4). However, crystals of the monoclinic $\beta^{\prime \prime}$ phase only grow when $\mathrm{M}=\mathrm{Fe}$ or $\mathrm{Cr}$, and not for another $\mathrm{M}\left(\mathrm{C}_{2} \mathrm{O}_{4}\right)_{3}{ }^{3-}$ anions. On the other hand, when using bromobenzene as the guest solvent high-quality crystals of the monoclinic $\beta^{\prime \prime}$ phase crystals have been obtained for $\mathrm{M}=\mathrm{Fe}^{3+}, \mathrm{Cr}^{3+}, \mathrm{Ga}^{3+}$, $\mathrm{Rh}^{3+}, \mathrm{Ru}^{3+}$, and $\mathrm{Mn}^{3+}$ (Tables 1 and 2).

\section{3 Bilayered triclinic $\alpha / \beta^{\prime \prime}$ and $\alpha /$ pseudo-k salts}

A third type of 4:1 salt has also been synthesised when using an unsymmetrical guest solvent which is too large to fit within the hexagonal cavities in the anion layer (Table 5). These unsymmetrical molecules do not sit centrally in the hexagonal cavity but instead the phenyl groups are displaced towards one face of the anion layer with a side group protruding on one side. The result is that both faces of the anion layer are not identical which leads to two different BEDT-TTF packing modes in adjacent donor layers (Fig. 6). Depending on the solvent in the hexagonal cavity the packing types are $\alpha / \beta^{\prime \prime}\left(\mathrm{PhCH}_{2} \mathrm{CN}, \mathrm{PhN}\left(\mathrm{CH}_{3}\right) \mathrm{CHO}, \mathrm{PhCOCH}_{3}, \mathrm{PhCH}(\mathrm{OH}) \mathrm{CH}_{3}\right)$ or a/pseudo-k $\left(1,2-\mathrm{Br}_{2} \mathrm{Ph}\right)$. The $\beta$ " and pseudo-k donor packing modes are discussed earlier (Figs 2 and 4) whilst the a packing is shown in Fig. 7.

The inclusion of sec-phenethyl alcohol $\left(\mathrm{PhCH}(\mathrm{OH}) \mathrm{CH}_{3}\right)$ in these salts is also of note owing to it being prepared from either the racemic $R / S$ or chiral $S$ molecule.[37] The $R / S$ bilayered salts have four crystallographically independent BEDT-TTF molecules in the asymmetric unit (with two belonging to the $a$ donor packing mode and two to the $\beta^{\prime \prime}$ ) in space group $P-1$, whilst the isostructural chiral $S$ salt has eight BEDT-TTFs, with four in each donor packing mode in space group P1. A small difference in the metal-insulator transition temperature is observed owing to the enantiomeric disorder of the $R$ and $S$ molecule in the racemic salt which is not found in the chiral $S$ salt.

\subsection{Chirality of the anion layers}

On the subject of chirality there is a significant difference between the tris(oxalato)metallates in the anion layers in the $\beta$ " and pseudo-к salts, though at first glance they may look identical. In the $\beta$ " salts each anion layer contains only a single enantiomer of $\mathrm{M}\left(\mathrm{C}_{2} \mathrm{O}_{4}\right)_{3^{3-}}$ with the adjacent anion layers containing only the opposite enantiomer to give an overall racemic lattice (Fig. 3). In the pseudo-k salts each anion layer contains a 50:50 mixture of the two enantiomer of $\mathrm{M}\left(\mathrm{C}_{2} \mathrm{O}_{4}\right)_{3}{ }^{3-}$, with alternating rows of $\Delta$ or $\Lambda$ enantiomers within a single anion layer, to once again give an overall racemic lattice (Fig. 5). When performing synthesis from racemic $\mathrm{M}\left(\mathrm{C}_{2} \mathrm{O}_{4}\right)_{3}{ }^{3-}$, crystals begin to grow within a couple of days, but during attempts to grow crystals from enantiopure $\mathrm{Cr}\left(\mathrm{C}_{2} \mathrm{O}_{4}\right)_{3}{ }^{3-}$ no crystals were obtained in the first 2 weeks.[31] The crystals obtained were of the racemic pseudo-к phase which suggests that partial racemisation occurred before crystals started to grow.

\section{3:1 radical cation-salts of BEDT-TTF with tris(oxalato)metallate(III)}

A new family of 3:1 salts was obtained when trying to include chiral (R)-(-)-carvone (Scheme 2$)$ into the hexagonal cavity as guest solvent molecule.[39-43] Using (R)-(-)-carvone on its own gave no crystals since it is likely that the molecule is too large to fit inside the cavity. However, using $(R)-(-)-$ 
carvone mixed with a second solvent resulted in chiral induction and the second solvent molecule is included in a radical-cation salt of BEDT-TTF with either a single enantiomer or an enantiomeric excess of the $\Delta-M\left(C_{2} \mathrm{O}_{4}\right)_{3}{ }^{3-}$ anion. This method has produced a family of semiconductors having the formula (BEDT-TTF $)_{3}\left[(\mathrm{~A}) \mathrm{M}\left(\mathrm{C}_{2} \mathrm{O}_{4}\right)_{3}\right]$.solvent $\left(\mathrm{M}=\mathrm{Cr}^{3+}, \mathrm{Al}^{3+} ; \mathrm{A}=\mathrm{Li}^{+}, \mathrm{Na}^{+}, \mathrm{NH}_{4}^{+}\right.$; solvent $=$nitromethane, acetonitrile, dichloromethane, $\mathrm{N}, \mathrm{N}$-dimethylformamide, ethanol) (Table 6).

These salts also consist of alternating anion and donor layers. The anion layers are similar to the $4: 1$ salts with a hexagonal packing of tris(oxalato)metallate and counter cation, though the hexagonal cavity size is smaller and accommodates the smaller solvents used in these salts (Fig. 8). All except the DMF salt have an asymmetric unit consisting of three crystallographically independent BEDT-TTFs; two of these BEDT-TTF molecules are parallel (A and B) whilst the third BEDT-TTF molecule (C) is at $90^{\circ}$ with respect to $A$ and $B$ in the $P 2{ }_{1}{ }_{2}{ }_{1}{ }_{1}$ salts, $45^{\circ}$ in the $P 2_{1}$ salts, or $80^{\circ}$ in the $P 1$ salts (Fig. $9 a-C$ ). The parallel BEDT-TTFs do not form a dimer since there are no close S...S contacts below the sum of the van der Waals radii $(<3.6 \AA)$. The charges on the donor molecules show considerable differences between the salts in this 3:1 family. Some salts show charge disproportionation with the monomer having a charge close to zero and the dimer having a higher charge close to +2 suggesting formation of a spin dimer. Meanwhile other salts show charges close to $0.66+(+/-0.1)$ for each of the three donors. The DMF salt has the $\theta$ packing motif (Fig. 9d) with two crystallographically independent BEDTTTF molecules.

Zhang et al. have synthesised antiferromagnetic semiconductor (BEDT-TTF) ${ }_{3} \mathrm{Cu}_{2}\left(\mathrm{C}_{2} \mathrm{O}_{4}\right)_{3}\left(\mathrm{CH}_{3} \mathrm{OH}\right)_{2}$ from BEDT-TTF and $\left(\mathrm{Et}_{3} \mathrm{NH}\right)_{2} \mathrm{Cu}\left(\mathrm{C}_{2} \mathrm{O}_{4}\right)_{2}$. There are three crystallographically independent BEDT-TTF molecules, one of which forms a stack along the $a$ axis, with the other two forming the neighbouring stack. There is a dihedral angle of $125-126^{\circ}$ between the two stacks. The anion layer includes two methanol molecules in each hexagonal cavity created by six oxalate-bridged copper atoms.[7] The antiferromagnetism arises from $\mathrm{d}$ - $\mathrm{d}$ interaction between the Jahn-Teller distorted oxalate-bridged $\mathrm{Cu}^{2+}$ atoms.

\section{2:1 radical cation-salts of BEDT-TTF with tris(oxalato)metallate(III) containing 18-crown-6}

In 2017 a new superconducting phase was discovered, only the $2^{\text {nd }}$ superconducting phase after the $4: 1 \beta^{\prime \prime}$ salts which were first reported in 1995. These superconductors have the formula $\beta^{\prime \prime}-$ (BEDT-TTF $)_{2}\left[\left(\mathrm{H}_{2} \mathrm{O}\right)\left(\mathrm{NH}_{4}\right)_{2} \mathrm{M}\left(\mathrm{C}_{2} \mathrm{O}_{4}\right)_{3}\right]$.18-crown-6, with $\mathrm{M}=\mathrm{Cr}^{3+}(\mathrm{Tc}=4.0-4.9 \mathrm{~K})$ or $\mathrm{M}=\mathrm{Rh}^{3+}(\mathrm{TC}=2.7 \mathrm{~K})$ (Table 7).[44,45]

Crystallising in triclinic space group $P-1$ the asymmetric unit consists of two crystallographically independent BEDT-TTF ${ }^{0.5+}$ cations, one $\mathrm{M}\left(\mathrm{C}_{2} \mathrm{O}_{4}\right)_{3}{ }^{3-}$ anion, one $\mathrm{H}_{2} \mathrm{O}$ molecule, two $\mathrm{NH}_{4}{ }^{+}$cations, and one 18-crown-6 molecule. The BEDT-TTF molecules adopt a similar $\beta$ "-packing arrangement to the 4:1 superconductors (Fig. 2) with the two crystallographically independent BEDT-TTF cations (A and $B$ ) having an AABBAABB pattern within each stack. Donor $B$ is ordered whilst donor $A$ shows disorder of a terminal ethylene group at one end only at $110 \mathrm{~K}$, which is directed towards the $\mathrm{NH}_{4}{ }^{+}$ cation in the anion layer. The anion layer adopts a similar hexagonal packing arrangement of $\mathrm{NH}_{4}{ }^{+}$ and $\mathrm{M}\left(\mathrm{C}_{2} \mathrm{O}_{4}\right)_{3}{ }^{3-}$ to the $4: 1$ salts, but instead of a guest solvent molecule, a single 18-crown-6 molecule protrudes into the hexagonal cavity of only one adjacent anion layer. The crystal structure has a superstructure with a repeating pattern of ABCDABCDA with BEDT-TTF molecules adopting a $\beta^{\prime \prime}$ packing motif (layer $A$ ), layers of $\mathrm{NH}_{4}{ }^{+}$and $\Lambda-M\left(C_{2} \mathrm{O}_{4}\right)_{3}{ }^{3-}$ (layer $B$ ), layers of $\left(\mathrm{H}_{2} \mathrm{O}\right)\left(\mathrm{NH}_{4}\right)$ 18-crown-6 (layer $\mathrm{C}$ ), and layers of $\mathrm{NH}_{4}{ }^{+}$and $\Delta-\mathrm{M}\left(\mathrm{C}_{2} \mathrm{O}_{4}\right)_{3}{ }^{3-}$ (layer D). This results in a 
packing arrangement with the widest gap between conducting BEDT-TTF layers where only a single donor packing motif is present (Fig. 10).[44,45]

For the Rh salt a Tc of $2.7 \mathrm{~K}$ was observed by transport measurement $\left(T_{\mathrm{CT}}\right)$ but zero resistivity could not be observed. A Tc of $2.5 \mathrm{~K}$ was observed on the magnetisation curve $\left(T_{\mathrm{CM}}\right)$ but it was not clear and the Meissner signal was small. By contrast, zero resistivity for the $\mathrm{Cr}$ salt could be clearly observed below $1.8 \mathrm{~K}$ and the Meissner signal was relatively large, although the transition was broader than those of normal superconducting salts, and the Meissner volume at $1.7 \mathrm{~K}$ was calculated as $11.5 \%$. There was a large difference between $T_{\mathrm{cT}}$ and $T_{\mathrm{cM}}$ of $4.0-4.9 \mathrm{~K}$ and $2.5 \mathrm{~K}$, respectively. The insulating layer of the $\mathrm{Cr}$ salt is thinner than that of the isostructual $\mathrm{Rh}$ salt which leads the Rh salt having a larger gap between BEDT-TTF layers and so the Rh salt a stronger 2D nature. The superconducting transition of the Rh salt may be extraordinarily broad because the 2D nature of the material makes the superconducting transition a Kosterlitz-Thouless (KT) transition.[56] I-V measurement also suggests that the $\mathrm{Cr}$ salt shows a close to perfect KosterlitzThouless transition.[44,45]

Another interesting 2:1 salt is the proton-conducting metal $\beta$ "-(BEDT-TTF $)_{4}\left[(\mathrm{~A}) \mathrm{M}\left(\mathrm{C}_{2} \mathrm{O}_{4}\right)_{3}\right]_{2}$. $\left[(\mathrm{A})_{2} 18\right.$ crown-6] $\left(\mathrm{H}_{2} \mathrm{O}\right)_{5}\left(\mathrm{M}=\mathrm{Cr}\right.$ or $\mathrm{Ga}, \mathrm{A}=\mathrm{NH}_{4}{ }^{+}$or $\left.\mathrm{H}_{3} \mathrm{O}^{+}\right)$(Table 7). Crystallising in triclinic space group $P$ 1 the asymmetric unit consists of two crystallographically independent BEDT-TTF ${ }^{0.5+}$ cations, one $\mathrm{M}\left(\mathrm{C}_{2} \mathrm{O}_{4}\right)_{3}{ }^{3-}$ anion, five $\mathrm{H}_{2} \mathrm{O}$ molecules, four $\mathrm{H}_{3} \mathrm{O}^{+} / \mathrm{NH}_{4}{ }^{+}$cations, and half an 18-crown-6 molecule. The crystal structure also has an ABCDABCDA superstructure, like the aforementioned 2:1 salt, but in this salt the crown ether molecules in layer $\mathrm{C}$ form a stack containing hydrogen-bonded chains of $\mathrm{A} / \mathrm{H}_{2} \mathrm{O}$ which is believed to mediate the proton conductivity through a diffusion mechanism (Fig. 11).[46,47]

\section{Other radical cation-salts of BEDT-TTF with tris(oxalato)metallate(III)}

Several phases have been produced by using tris(oxalato)ferrate with different counter cations: $\beta^{\prime}$ (BEDT-TTF $)_{5}\left[\mathrm{Fe}\left(\mathrm{C}_{2} \mathrm{O}_{4}\right)_{3}\right] \cdot\left(\mathrm{H}_{2} \mathrm{O}\right)_{2} \cdot \mathrm{CH}_{2} \mathrm{Cl}_{2}[48]$ from tetraethylammonium, $\eta$-(BEDTTTF $)_{4}\left(\mathrm{H}_{2} \mathrm{O}\right)$ LiFe $\left(\mathrm{C}_{2} \mathrm{O}_{4}\right)_{3}[43]$ from lithium, a'"-(BEDT-TTF) ${ }_{9}\left[\mathrm{Fe}\left(\mathrm{C}_{2} \mathrm{O}_{4}\right)_{3}\right]_{8} \mathrm{Na}_{18}\left(\mathrm{H}_{2} \mathrm{O}\right)_{24}$ [49] from sodium, $a-$ (BEDT-TTF) ${ }_{10}\left(18\right.$-crown-6) ${ }_{6} \mathrm{~K}_{6}\left[\mathrm{Fe}\left(\mathrm{C}_{2} \mathrm{O}_{4}\right)_{3}\right]_{4}\left(\mathrm{H}_{2} \mathrm{O}\right)_{24}[49]$ from potassium, and a-(BEDTTTF) ${ }_{12}\left[\mathrm{Fe}\left(\mathrm{C}_{2} \mathrm{O}_{4}\right)_{3}\right]_{2} \cdot\left(\mathrm{H}_{2} \mathrm{O}\right)_{n}[50]$ from potassium or caesium (Table 8$)(n=15$ or 16$)$.

Semiconductor $\beta^{\prime}-(\mathrm{BEDT}-\mathrm{TTF})_{5}\left[\mathrm{Fe}\left(\mathrm{C}_{2} \mathrm{O}_{4}\right)_{3}\right] \cdot\left(\mathrm{H}_{2} \mathrm{O}\right)_{2} \cdot \mathrm{CH}_{2} \mathrm{Cl}_{2}[48]$ grown from tetraethylammonium tris(oxalato)ferrate has alternating donor and anion layers. The BEDT-TTF layers adopt a packing similar to $\beta^{\prime}$ with alternate donor layers having different close $S$...S contacts. Each anion layer consists of a single enantiomer of $\left[\mathrm{Fe}\left(\mathrm{C}_{2} \mathrm{O}_{4}\right)_{3}\right]^{3-}$ with the next anion layer consisting of the opposite enantiomer. $\left[\mathrm{Fe}\left(\mathrm{C}_{2} \mathrm{O}_{4}\right)_{3}\right]^{3-}$ anions are arranged in a parallelogram occupied by two water and one dichloromethane molecule (Fig. 12a). Another semiconducting 5:1 salt, $a^{\prime \prime}-(\mathrm{BEDT}-\mathrm{TTF})_{5}\left[\mathrm{Ga}\left(\mathrm{C}_{2} \mathrm{O}_{4}\right)_{3}\right] \cdot\left(\mathrm{H}_{2} \mathrm{O}\right)_{3.4^{\circ}} \cdot(\mathrm{EtOH})_{0.6},[29]$ differs in that each anion layer contains a 50:50 mixture of $\Delta$ - and $\Lambda-\left[\mathrm{Fe}\left(\mathrm{C}_{2} \mathrm{O}_{4}\right)_{3}\right]^{3-}$ anions, which alternate in the $a$ direction, with disorder ethanol and water molecules in a void on one side of the parallelogram.

Semiconductor $\eta$-(BEDT-TTF $)_{4}\left(\mathrm{H}_{2} \mathrm{O}\right) \mathrm{LiFe}\left(\mathrm{C}_{2} \mathrm{O}_{4}\right)_{3}[43]$ grown from lithium tris(oxalato)ferrate also has alternating donor and anion layers. The BEDT-TTF molecules adopt a $\eta$ packing arrangement (Fig. 13a). Each anion layer consists of a single enantiomer of $\left[\mathrm{Fe}\left(\mathrm{C}_{2} \mathrm{O}_{4}\right)_{3}\right]^{3-}$ with the next anion layer consisting of the opposite enantiomer. The anion layers have a honeycomb network of $\mathrm{Li}^{+}$and $\mathrm{M}$ (oxalate) ${ }_{3}{ }^{3-}$ that includes a water molecule which elongates the hexagon in the $c$ direction compared to other salts of 
this type grown from ammonium or potassium tris(oxalato)ferrate (Fig. 13b). The hexagonal cavity in this salt contains heavily disordered dichloromethane which could not be resolved.

Semiconductor a'"'-(BEDT-TTF) ${ }_{9}\left[\mathrm{M}\left(\mathrm{C}_{2} \mathrm{O}_{4}\right)_{3}\right]_{8} \mathrm{Na}_{18}\left(\mathrm{H}_{2} \mathrm{O}\right)_{24}[42,49]$ was grown from sodium tris(oxalato)ferrate or -chromate and is a multi-layered salt of type $A B C D A B C D A B C D$. The $A$ layers consist of only BEDT-TTF, B and D layers consist of tris(oxalato)metallate(III) and sodium, and the $\mathrm{C}$ layers consist of sodium and water (Fig. 14). The two enantiomeric forms of $\left[\mathrm{Fe}\left(\mathrm{C}_{2} \mathrm{O}_{4}\right)_{3}\right]^{3-}, \Delta$ and $\Lambda$, are separated by a layer built up of columns of $\mathrm{Na}^{+}$ions and columns of water molecules (Fig. 14). In the tris(oxalato)metallate layers $\operatorname{six}\left[\mathrm{M}\left(\mathrm{C}_{2} \mathrm{O}_{4}\right)_{3}\right]^{3-}$ anions form close contacts with two 8-coordinate sodium ions.

Semiconductor a-(BEDT-TTF) ${ }_{10}(18-c r o w n-6)_{6} \mathrm{~K}_{6}\left[\mathrm{Fe}\left(\mathrm{C}_{2} \mathrm{O}_{4}\right)_{3}\right]_{4}\left(\mathrm{H}_{2} \mathrm{O}\right)_{24}[49]$ was grown from potassium tris(oxalato)ferrate and is a multi-layered salt of type $A B C B A B C B A$. The $A$ layers consist of only BEDTTTF molecules, $B$ layers consist of rows of alternating $\Delta$ - and $\Lambda$ - $\left[\mathrm{Fe}\left(\mathrm{C}_{2} \mathrm{O}_{4}\right)_{3}\right]^{3-}$ with $\mathrm{H}_{2} \mathrm{O}$, and 18-crown-6 with complexed $\mathrm{K}^{+}$ions, $\mathrm{C}$ layers consist of columns of $18-$ crown- 6 molecules with complexed $\mathrm{K}^{+}$(Fig. 15).

a-(BEDT-TTF) ${ }_{12}\left[\mathrm{Fe}\left(\mathrm{C}_{2} \mathrm{O}_{4}\right)_{3}\right]_{2} \cdot\left(\mathrm{H}_{2} \mathrm{O}\right)_{n}[50]$ grown from potassium or caesium tris(oxalato)ferrate differ only in the number of $\mathrm{H}_{2} \mathrm{O}$ molecules, 15 or 16 , respectively. The novel anion layer packing consists of a tris(oxalato)ferrate surrounded by $\mathrm{H}_{2} \mathrm{O}$ molecules in hydrogen bonded chains (Fig. 12b).

The coexistence of ferromagnetism and metallic conductivity was discovered in the first magnetic molecular metal (BEDT-TTF) $x$ [ $\left.\mathrm{MnCr}\left(\mathrm{C}_{2} \mathrm{O}_{4}\right)_{3}\right] \cdot \mathrm{CH}_{2} \mathrm{Cl}_{2} \quad(x=<3)$.[6] The BEDT-TTF layers show metallic behaviour down to $0.3 \mathrm{~K}$ whilst the bimetallic honeycomb tris(oxalato)metallate layers are responsible for ferromagnetic ordering below $5.5 \mathrm{~K}$.[6] The isostructural paramagnetic metal (BEDT$\mathrm{TTF})_{2.53}\left[\mathrm{MnRh}\left(\mathrm{C}_{2} \mathrm{O}_{4}\right)_{3}\right] \cdot \mathrm{CH}_{2} \mathrm{Cl}_{2}$ has also been synthesized which helped to clarify the incommensurate nature of the conducting and magnetic layers.[51,52]

\section{Radical cation-salts of BEDT-TTF with tris(oxalato)germanate(IV)}

Changing the charge on the tris(oxalato)metallate to 4- produces very different structures compared to the tris(oxalato)metallate(III) radical-cation salts (Table 9). There are four examples using the tris(oxalato)germanate(IV) anion, all of which are semiconductors: (BEDT-TTF) ${ }_{2}\left[\mathrm{Ge}\left(\mathrm{C}_{2} \mathrm{O}_{4}\right)_{3}\right] \cdot \mathrm{PhCN}$,[53] (BEDT-TTF) $)_{5}\left[\mathrm{Ge}\left(\mathrm{C}_{2} \mathrm{O}_{4}\right)_{3}\right]_{2}$,[54] (BEDT-TTF) ${ }_{7}\left[\mathrm{Ge}\left(\mathrm{C}_{2} \mathrm{O}_{4}\right)_{3}\right]_{2}\left(\mathrm{CH}_{2} \mathrm{Cl}_{2}\right)_{0.87}\left(\mathrm{H}_{2} \mathrm{O}\right)_{0.09},[54]$ and (BEDT$\mathrm{TTF})_{4} \mathrm{Ge}\left(\mathrm{C}_{2} \mathrm{O}_{4}\right)_{3} \cdot\left(\mathrm{CH}_{2} \mathrm{Cl}_{2}\right)_{0.50}$. [55] None of these salts have anion layers with the $2 \mathrm{D}$ honeycomb tris(oxalato)metallate sheets found in the 3- salts. (BEDT-TTF) ${ }_{2}\left[\mathrm{Ge}\left(\mathrm{C}_{2} \mathrm{O}_{4}\right)_{3}\right] \cdot \mathrm{PhCN}[53]$ does not contain alternating anion and donor layers but instead has BEDT-TTF dimers in a checkerboard arrangement with $\left[\mathrm{Ge}\left(\mathrm{C}_{2} \mathrm{O}_{4}\right)_{3}\right]^{2-}$ anions and separate benzonitrile layers (Fig. 16). (BEDT-TTF) $)_{5}\left[\mathrm{Ge}\left(\mathrm{C}_{2} \mathrm{O}_{4}\right)_{3}\right]_{2}[54]$ also has a checkerboard arrangement of donors and anions with BEDT-TTFs forming diagonal stacks of five molecules, with a crystallographically unique molecule sandwiched between two pairs of dimers (Fig. 16). Each $\left[\mathrm{Ge}\left(\mathrm{C}_{2} \mathrm{O}_{4}\right)_{3}\right]^{2-}$ is disordered between the $\Delta$ and $\Lambda$ enantiomers when grown from several different solvents; when using $(R)-(-)$-carvone a Flack parameter of $0.43(3)$ is observed. (BEDTTTF $)_{7}\left[\mathrm{Ge}\left(\mathrm{C}_{2} \mathrm{O}_{4}\right)_{3}\right]_{2}\left(\mathrm{CH}_{2} \mathrm{Cl}_{2}\right)_{0.87}\left(\mathrm{H}_{2} \mathrm{O}\right)_{0.09}$, [54] and (BEDT-TTF) ${ }_{4} \mathrm{Ge}\left(\mathrm{C}_{2} \mathrm{O}_{4}\right)_{3} \cdot\left(\mathrm{CH}_{2} \mathrm{Cl}_{2}\right)_{0.50}$. [55] both have segregated anion and donor layers. The anion layers in the both are made up of $\left[\mathrm{Ge}\left(\mathrm{C}_{2} \mathrm{O}_{4}\right)_{3}\right]^{2-}$ segregated into $\Delta$ and $\Lambda$ enantiomer pairs separated by dichloromethane molecules (Fig. 17).

\section{CONCLUSIONS}

This review highlights the diversity of packing arrangements of the tris(oxalato)metallate anion with the organosulphur donor molecule BEDT-TTF. These radical-cation salts combine magnetism with conductivity in an extensive family of insulators, semiconductors, metals and superconductors. No 
novel effects upon the bulk physical properties have been observed owing to the interplay between the discrete anion and cation layers. The inclusion of other building blocks such as guest solvents molecules, counter cations and crown ethers have produced a wealth of multifunctional materials including properties such as proton conductivity.

The synthesis of materials combining chirality and conductivity are important to explore electrical magneto-chiral anisotropy. This has been observed in bismuth helices,[57] and in carbon nanotubes,[58] where the resistivity along nanotubes of opposing chirality differs in a coaxial magnetic field. The use of tris(oxalato)metallate anions in BEDT-TTF salts offers the potential to synthesise chiral conductors. Chiral semiconductors have already been synthesised via chiral induction in the presence of $(R)-(-)$-carvone,[39-43] and many novel packing arrangements of $\Delta$ - and $\Lambda$ $\left[\mathrm{M}\left(\mathrm{C}_{2} \mathrm{O}_{4}\right)_{3}\right]^{3-}$ enantiomers have been observed in racemic radical-cation salts. Other racemic and chiral anions that have been used to produce radical-cation salts with BEDT-TTF include Fe(croconate) $)_{3}$,[59] $\mathrm{Cr}\left(2,2^{\prime} \text {-bipy)(oxalate) }\right)_{2}$,[60] $\mathrm{Sb}_{2}$ (L-tartrate) ${ }_{2}$,[61] TRISPHAT,[62] B(malate) ${ }_{2},[63]$ and $\mathrm{Fe}\left(\mathrm{C}_{6} \mathrm{O}_{4} \mathrm{Cl}_{2}\right)_{3}$.[64]

The use of enantiopure donor molecules based on TTF or BEDT-TTF,[65] with the tris(oxalato)metallate anion is another prospect. Electrical magneto-chiral anisotropy has recently been observed in enantiopure radical-cation salts of $(S, S)$ - and $(R, R)$ - (DM-EDT-TTF) ${ }_{2} \mathrm{ClO}_{4}[66]$ which crystallise in enantiomorphic space groups $\mathrm{PG}_{2} 22$ and $P 6_{4} 22$, and show metallic behavior down to $40 \mathrm{~K}$. Enantiopure donors have previously been used to produce salts with the meso stereoisomer of $\left[\mathrm{Fe}_{2}(\text { oxalate })_{5}\right]^{4-}[67]$ or with racemic $\mathrm{Fe}\left(\mathrm{C}_{6} \mathrm{O}_{4} \mathrm{Cl}_{2}\right)_{3} \cdot[68]$

\section{ACKNOWLEDGEMENTS}

The author would like to thank Peter Day for giving him the opportunity to work in this field and is very grateful to his many co-workers and everyone whose name appears in the reference section who have made this such an enjoyable area of research. The work performed by the author at Nottingham Trent University has been supported by Royal Society [Research Grants (RG100853 and RG081209), International Exchange Scheme (IE130367 and IE150152), and International Joint Project (JP0869972)] and a Royal Society Leverhulme Trust Senior Research Fellowship.

\section{REFERENCES}

[1] J. P. Ferraris, D. O. Cowan, V. Walatka, J. H. Perlstein, Electron transfer in a new highly conducting donor-acceptor complex, J. Am. Chem. Soc., 95 (1973) 948-949.

[2] J. R. Ferraro, J. M. Williams, Introduction to Synthetic Electrical Conductors, (1987) Academic Press, Orlando, FL; T. Ishiguro, K. Yamaji, Organic Superconductors, (1990) Springer-Verlag, Heidelberg, Germany; J. M. Williams, Organic Superconductors: Synthesis, Structure, Properties and Theory, (1991) Prentice-Hall, Englewood Cliffs, NJ.

[3] D. Jérome, A. Mazaud, M. Ribault and K. Bechgaard, J. Phys. Lett. (Paris) 41 (1980) 95-98.

[4] A. M. Kini, U. Geiser, H. H. Wang, K. D. Carlson, J. M. Williams, W. K. Kwok, K. G. Vandervoort, J. E. Thompson and D. L. Stupka, A new ambient-pressure organic superconductor $\mathrm{k}-(\mathrm{ET})_{2} \mathrm{Cu}\left[\mathrm{N}(\mathrm{CN})_{2}\right] \mathrm{Br}$, with the highest transition temperature yet observed (inductive onset $\mathrm{TC}=11.6 \mathrm{~K}$, resistive onset $=$ 12.5 K), Inorganic Chemistry, 29 (1990) 2555-2557; J. E. Schirber, D. L. Overmyer, J. M. Williams, A. M. 
Kini, H. H. Wang, Pressure dependence of Tc in the highest Tc organic superconductor, K-(BEDTTTF ${ }_{2} \mathrm{Cu}\left[\mathrm{N}(\mathrm{CN})_{2}\right] \mathrm{Br}$, Physica C: Superconductivity, 170 (1990) 231-232; J. M. Williams, A. M. Kini, H. H. Wang, K. D. Carlson, U. Geiser, L. K. Montgomery, G. J. Pyrka, D. M. Watkins and J. M. Kommers, From semiconductor-semiconductor transition $(42 \mathrm{~K})$ to the highest-Tc organic superconductor, $\mathrm{K}-$ (ET)2Cu[N(CN)2]Cl (TC = $12.5 \mathrm{~K}$ ), Inorganic Chemistry, 29 (1990) 3272-3274; H. Ito, T. Ishiguro, M. Kubota, G. Saito, Metal-Nonmetal Transition and Superconductivity Localization in the TwoDimensional Conductor K-(BEDT-TTF) ${ }_{2} \mathrm{Cu}\left[\mathrm{N}(\mathrm{CN})_{2}\right] \mathrm{Cl}$ under pressure, J. Phys. Soc. Jpn, 65 (1996) 29872993; H. Taniguchi, M. Miyashita, K. Uchiyama, K. Satoh, N. Mori, H. Okamoto, K. Miyagawa, K. Kanoda, M. Hedo, Y. Uwatoko, Superconductivity at $14.2 \mathrm{~K}$ in Layered Organics under Extreme Pressure, J. Phys. Soc. Jpn. 72 (2003) 468-471.

[5] A. W. Graham, M. Kurmoo, P. Day, $\beta^{\prime \prime}-(\text { bedt-ttf })_{4}\left[\left(\mathrm{H}_{2} \mathrm{O}\right) \mathrm{Fe}\left(\mathrm{C}_{2} \mathrm{O}_{4}\right)_{3}\right] \cdot \mathrm{PhCN}$ : The first molecular superconductor containing paramagnetic metal ions, J. Chem. Soc. Chem. Commun., (1995) 20612062.

[6] E. Coronado, J. R. Galán-Mascarós, C. J. Gómez-García, V. Laukhin, Coexistence of ferromagnetism and metallic conductivity in a molecule-based layered compound, Nature, 408 (2000) 447-449; A. Alberola, E. Coronado, J. R. Galán-Mascarós, C. Giménez-Saiz and C. J. Gómez-García, J. Am. Chem. Soc., 2003, 125, 10774-10775.

[7] B. Zhang, Y. Zhang, D. Zhu, (BEDT-TTF $)_{3} \mathrm{Cu}_{2}\left(\mathrm{C}_{2} \mathrm{O}_{4}\right)_{3}\left(\mathrm{CH}_{3} \mathrm{OH}\right)_{2}$ : an organic-inorganic hybrid antiferromagnetic semiconductor, Chem. Commun., 48 (2012) 197-199.

[8] M. Kurmoo, A. W. Graham, P. Day, S. J. Coles, M. B. Hursthouse, J. L Caulfield, J. Singleton, F. L. Pratt, W. Hayes, Superconducting and Semiconducting Magnetic Charge Transfer Salts: (BEDTTTF $)_{4} \mathrm{AFe}\left(\mathrm{C}_{2} \mathrm{O}_{4}\right)_{3} \cdot \mathrm{C}_{6} \mathrm{H}_{5} \mathrm{CN}\left(\mathrm{A}=\mathrm{H}_{2} \mathrm{O}, \mathrm{K}, \mathrm{NH}_{4}\right)$, J. Am. Chem. Soc., 117 (1995) 12209-12217.

[9] L. Martin, S. S. Turner, P. Day, P. Guionneau, J. A. K. Howard, D. E. Hibbs, M. E. Light, M. B. Hursthouse, M. Uruichi, K. Yakushi, Crystal Chemistry and Physical Properties of Superconducting and Semiconducting Charge Transfer Salts of the Type (BEDT-TTF) ${ }_{4}\left[\mathrm{~A}^{\prime} \mathrm{M}^{\prime \prime \prime}\left(\mathrm{C}_{2} \mathrm{O}_{4}\right)_{3}\right] \cdot \mathrm{PhCN}\left(\mathrm{A}^{\prime}=\mathrm{H}_{3} \mathrm{O}, \mathrm{NH}_{4}, \mathrm{~K}\right.$; $\mathrm{M}^{\mathrm{III}}=\mathrm{Cr}$, Fe, Co, Al; BEDT-TTF = Bis(ethylenedithio)tetrathiafulvalene), Inorg. Chem., 40 (2001) 13631371.

[10] A. Akutsu-Sato, H. Akutsu, J. Yamada, S. Nakatsuji, S. S. Turner, P. Day, Suppression of superconductivity in a molecular charge transfer salt by changing guest molecule: $\beta$ "-(BEDTTTF $)_{4}\left[\left(\mathrm{H}_{3} \mathrm{O}\right) \mathrm{Fe}\left(\mathrm{C}_{2} \mathrm{O}_{4}\right)_{3}\right]\left(\mathrm{C}_{6} \mathrm{H}_{5} \mathrm{CN}\right)_{x}\left(\mathrm{C}_{5} \mathrm{H}_{5} \mathrm{~N}\right)_{1-\mathrm{x}}$, J. Mater. Chem., 17 (2007) 2497-2499.

[11] T. G. Prokhorova, L. I. Buravov, E. B. Yagubskii, L. V. Zorina, S. S. Khasanov, S.V. Simonov, R. P. Shibaeva, A. V. Korobenko, V. N. Zverev, Effect of electrocrystallization medium on quality, structural features, and conducting properties of single crystals of the (BEDT-TTF) ${ }_{4} \mathrm{~A}^{\prime}\left[\mathrm{Fe}^{\prime \prime \prime}\left(\mathrm{C}_{2} \mathrm{O}_{4}\right)_{3}\right] \cdot \mathrm{G}$ family, CrystEngComm, 13 (2011) 537-545.

[12] S. Rashid, S. S. Turner, P. Day, J. A. K. Howard, P. Guionneau, E. J. L. Mclnnes, F. E. Mabbs, R. J. H. Clark, S. Firth, T. Biggs, New superconducting charge-transfer salts (BEDT-TTF) ${ }_{4}\left[A \cdot M\left(C_{2} \mathrm{O}_{4}\right)_{3}\right] \cdot C_{6} \mathrm{H}_{5} \mathrm{NO}_{2}$ $\left(\mathrm{A}=\mathrm{H}_{3} \mathrm{O}\right.$ or $\mathrm{NH}_{4}, \mathrm{M}=\mathrm{Cr}$ or Fe, BEDT-TTF = bis(ethylenedithio)tetrathiafulvalene), J. Mater. Chem., 11 (2001) 2095-2101.

[13] S. Q. Sun, P. J. Wu, Q. C. Zhang, D. B. Zhu, The New Semiconducting Magnetic Charge Transfer Salt (BEDT-TTF $)_{4} \cdot \mathrm{H}_{2} \mathrm{O} \cdot \mathrm{Fe}\left(\mathrm{C}_{2} \mathrm{O}_{4}\right)_{3} \cdot \mathrm{C}_{6} \mathrm{H}_{5} \mathrm{NO}_{2}$ : Crystal Structure and Physical Properties., Mol. Cryst. Liq. Cryst., 319 (1998) 259-269. 
[14] S. Q. Sun, P. J. Wu, Q. C. Zhang, D. B. Zhu, The new semiconducting magnetic charge transfer salt (BEDT-TTF) $)_{4} \cdot \mathrm{H}_{2} \mathrm{O} \cdot \mathrm{Fe}\left(\mathrm{C}_{2} \mathrm{O}_{4}\right)_{3} \cdot \mathrm{C}_{6} \mathrm{H}_{5} \mathrm{NO}_{2}$ : Crystal structure and physical properties, Synth. Met., 94 (1998) 161-166.

[15] T. G. Prokhorova, L. I. Buravov, E. B. Yagubskii, L. V. Zorina, S. V. Simonov, V. N. Zverev, R. P. Shibaeva, E. Canadell, Effect of Halopyridine Guest Molecules on the Structure and Superconducting Properties of $\beta^{\prime \prime}$-[Bis(ethylenedithio)tetrathiafulvalene $]_{4}\left(\mathrm{H}_{3} \mathrm{O}\right)\left[\mathrm{Fe}\left(\mathrm{C}_{2} \mathrm{O}_{4}\right)_{3}\right] \cdot$ Guest Crystals, Eur. J. Inorg. Chem., 2015 (2015) 5611-5620.

[16] E. Coronado, S. Curreli, C. Giménez-Saiz, C. J. Gómez-García, A novel paramagnetic molecular superconductor formed by bis(ethylenedithio)tetrathiafulvalene, tris(oxalato) ferrate(III) anions and bromobenzene as guest molecule: $\mathrm{ET}_{4}\left[\left(\mathrm{H}_{3} \mathrm{O}\right) \mathrm{Fe}\left(\mathrm{C}_{2} \mathrm{O}_{4}\right)_{3}\right] \cdot \mathrm{C}_{6} \mathrm{H}_{5} \mathrm{Br}$, J. Mater. Chem., 15 (2005) 1429-1436.

[17] L. V. Zorina, S. S. Khasanov, S. V. Simonov, R. P. Shibaeva, P. O. Bulanchuk, V. N. Zverev, E. Canadell, T. G. Prokhorova, E. B. Yagubskii, Structural phase transition in the $\beta^{\prime \prime}-(\mathrm{BEDT}-\mathrm{TTF})_{4} \mathrm{H}_{3} \mathrm{O}\left[\mathrm{Fe}\left(\mathrm{C}_{2} \mathrm{O}_{4}\right)_{3}\right] \cdot \mathrm{G}$ crystals (where $G$ is a guest solvent molecule), CrystEngComm, 14 (2012) 460-465.

[18] E. Coronado, S. Curreli, C. Giménez-Saiz, C. J. Gómez-García, The series of molecular conductors and superconductors $\mathrm{ET}_{4}\left[\mathrm{AFe}\left(\mathrm{C}_{2} \mathrm{O}_{4}\right)_{3}\right] \cdot \mathrm{PhX}$ (ET = bis(ethylenedithio)tetrathiafulvalene; $\left(\mathrm{C}_{2} \mathrm{O}_{4}\right)^{2-}=$ oxalate; $\mathrm{A}^{+}=\mathrm{H}_{3} \mathrm{O}^{+}, \mathrm{K}^{+} ; \mathrm{X}=\mathrm{F}, \mathrm{Cl}, \mathrm{Br}$, and I): Influence of the halobenzene guest molecules on the crystal structure and superconducting properties, Inorg. Chem., 51 (2012) 1111-1126.

[19] A. Akutsu-Sato, A. Kobayashi, T. Mori, H. Akutsu, J. Yamada, S. Nakatsuji, S. S. Turner, P. Day, D. A. Tocher, M. E. Light, M. B. Hursthouse, Structures and Physical Properties of New $\beta^{\prime}$-BEDT-TTF TrisOxalatometallate (III) Salts Containing Chlorobenzene and Halomethane Guest Molecules, Synth. Met., 152 (2005) 373-376.

[20] E. Coronado, S. Curreli, C. Gimenez-Saiz, C J. Gómez-García, New magnetic conductors and superconductors based on BEDT-TTF and BEDS-TTF, Synth. Met., 154 (2005) 245-248.

[21] L. Zorina, T. Prokhorova, S. Simonov, S. Khasanov, R. Shibaeva, A. Manakov, V. Zverev, L. Buravov, E. Yagubskii, Structure and magnetotransport properties of the new quasi-two-dimensional molecular metal $\beta^{\prime \prime}$-(BEDT-TTF) ${ }_{4} \mathrm{H}_{3} \mathrm{O}\left[\mathrm{Fe}\left(\mathrm{C}_{2} \mathrm{O}_{4}\right)_{3}\right] \cdot \mathrm{C}_{6} \mathrm{H}_{4} \mathrm{Cl}_{2}$, J. Exp. Theor. Phys., 106 (2008) 347-354.

[22] T. G. Prokhorova, S. S. Khasanov, L. V. Zorina, L. I. Buravov, V. A. Tkacheva, A. A. Baskakov, R. B. Morgunov, M. Gener, E. Canadell, R. P. Shibaeva, E. B. Yagubskii, Molecular Metals Based on BEDTTTF Radical Cation Salts with Magnetic Metal Oxalates as Counterions: $\beta$ "-(BEDT$\mathrm{TTF})_{4} \mathrm{~A}\left[\mathrm{M}\left(\mathrm{C}_{2} \mathrm{O}_{4}\right)_{3}\right] \cdot \mathrm{DMF}\left(\mathrm{A}=\mathrm{NH}_{4}{ }^{+}, \mathrm{K}^{+} ; \mathrm{M}=\mathrm{Cr}^{\prime \prime \prime}, \mathrm{Fe}{ }^{\mathrm{III}}\right)$, Adv. Funct. Mater., 13 (2003) 403-411.

[23] S. S. Turner, P. Day, K. M. A. Malik, M. B. Hursthouse, S. J. Teat, E. J. MacLean, L. Martin, S. A. French, Effect of included solvent molecules on the physical properties of the paramagnetic charge transfer salts $\beta^{\prime \prime}$-(bedt-ttf) ${ }_{4}\left[\left(\mathrm{H}_{3} \mathrm{O}\right) \mathrm{Fe}\left(\mathrm{C}_{2} \mathrm{O}_{4}\right)_{3}\right]$.solvent (bedt-ttf $=$ bis(ethylenedithio)tetrathiafulvalene), Inorg. Chem., 38 (1999) 3543-3549.

[24] A. I. Coldea, A. F. Bangura, J. Singleton, A. Ardavan, A. Akutsu-Sato, H. Akutsu, S. S. Turner, P. Day, Fermi-surface topology and the effects of intrinsic disorder in a class of charge-transfer salts containing magnetic ions: $\beta "-(B E D T-T T F)_{4}\left[\left(\mathrm{H}_{3} \mathrm{O}\right) M\left(\mathrm{C}_{2} \mathrm{O}_{4}\right)_{3}\right] \cdot Y\left(M=\mathrm{Ga}, \mathrm{Cr}, \mathrm{Fe} ; \mathrm{Y}=\mathrm{C}_{5} \mathrm{H}_{5} \mathrm{~N}\right)$, Phys. Rev. B, 69 (2004) 085112.

[25] R. Kanehama, Y. Yoshino, T. Ishii, T. Manabe, H. Hara, H. Miyasaka, H. Matsuzaka, M. Yamashita, M. Katada, H. Nishikawa, I. Ikemoto, Syntheses and physical properties of new charge-transfer salts 
consisting of a conducting BEDT-TTF column and magnetic 1D or 2D Fe(III) networks, Synth. Met., 133 (2003) 553-554.

[26] H. Akutsu, A. Akutsu-Sato, S. S. Turner, D. Le Pevelen, P. Day, V. Laukhin, A. Klehe, J. Singleton, D. A. Tocher, M. R. Probert, J. A. K. Howard, Effect of included guest molecules on the normal state conductivity and superconductivity of $\beta^{\prime \prime}-(\mathrm{ET})_{4}\left[\left(\mathrm{H}_{3} \mathrm{O}\right) \mathrm{Ga}\left(\mathrm{C}_{2} \mathrm{O}_{4}\right)_{3}\right] \cdot \mathrm{G}(\mathrm{G}=$ pyridine, nitrobenzene). J. Am. Chem. Soc., 124 (2002) 12430-12431.

[27] H. Akutsu, A. Akutsu-Sato, S. S. Turner, P. Day, D. A. Tocher, M. R. Probert, J. A. K. Howard, D. Le Pevelen, A.-K. Klehe, J. Singleton, V. Laukhin, Structures and properties of new superconductors, $\beta^{\prime \prime}-$ $(\mathrm{ET})_{4}\left[\left(\mathrm{H}_{3} \mathrm{O}\right) \mathrm{Ga}\left(\mathrm{C}_{2} \mathrm{O}_{4}\right)_{3}\right] \mathrm{Sol}[\mathrm{Sol}=$ nitrobenzene and pyridine], Synth. Met., 137 (2003) 1239-1240.

[28] T. G. Prokhorova, L. I. Buravov, E. B. Yagubskii, L. V. Zorina, S. V. Simonov, R. P. Shibaeva, V. N. Zverev, Metallic Bi- and Monolayered Radical Cation Salts Based on Bis(ethylenedithio)tetrathiafulvalene (BEDT-TTF) with the Tris(oxalato)gallate Anion, Eur. J. Inorg. Chem., (2014) 39333940.

[29] T. G. Prokhorova, E. B. Yagubskii, L. V. Zorina, S. V. Simonov, V. N. Zverev, R. P. Shibaeva, L. I. Buravov, Specific Structural Disorder in Anion Layer and Its Influence on Conducting Properties of New Crystals of (BEDT-TTF) ${ }_{4} \mathrm{~A}^{+}\left[\mathrm{M}^{3+}(\mathrm{ox})_{3}\right] \mathrm{G}$ Family, Where $\mathrm{G}$ is 2-Halopyridine; $\mathrm{M}$ Is $\mathrm{Cr}$, Ga; $\mathrm{A}^{+}$Is $\left[\mathrm{K}_{0.8}\left(\mathrm{H}_{3} \mathrm{O}\right)_{0.2}\right]^{+}$, Crystals, 8 (2018) 92.

[30] L. Martin, S. S. Turner, P. Day, F. E. Mabbs, E. J. L. Mclnnes, New molecular superconductor containing paramagnetic chromium (III) ions, Chem. Commun., (1997) 1367-1368;

[31] L. Martin, S. S. Turner, P. Day, K. M. A. Malik, S. J. Coles, M. B. Hursthouse, Polymorphism based on molecular stereoisomerism in tris(oxalato) $\mathrm{Cr}$ (III) salts of bedt-ttf [bis(ethylenedithio)tetrathiafulvalene], Chem. Commun., (1999) 513-514.

[32] S. Rashid, S. S. Turner, D. Le Pevelen, P. Day, M. E. Light, M. B. Hursthouse, S. Firth, R. J. H. Clark, $\beta^{\prime \prime}$-(BEDT-TTF) ${ }_{4}\left[\left(\mathrm{H}_{3} \mathrm{O}\right) \mathrm{Cr}\left(\mathrm{C}_{2} \mathrm{O}_{4}\right)_{3}\right] \mathrm{CH}_{2} \mathrm{Cl}_{2}$ : Effect of included solvent on the structure and properties of a conducting molecular charge-transfer salt, Inorg. Chem., 40 (2001) 5304-5306.

[33] L. Martin, A. L. Morritt, J. R. Lopez, Y. Nakazawa, H. Akutsu, S. Imajo, Y. Ihara, B. Zhang, Y. Zhang, Y. Guo, Molecular Conductors from bis(ethylenedithio)tetrathiafulvalene with tris(oxalato)rhodate, Dalton Trans., 46 (2017) 9542-9548.

[34] T. G. Prokhorova, L. V. Zorina, S. V. Simonov, V. N. Zverev, E. Canadell, R. P. Shibaeva, E. B. Yagubskii, The first molecular superconductor based on BEDT-TTF radical cation salt with paramagnetic tris(oxalato)ruthenate anion, CrystEngComm, 15 (2013) 7048-7055.

[35] S. Benmansour, Y. Sánchez-Máñez, C. J. Gómez-García, Mn-Containing Paramagnetic Conductors with Bis(ethylenedithio)tetrathiafulvalene (BEDT-TTF), Magnetochemistry, 3 (2017) 7.

[36] H. Akutsu, A. Akutsu-Sato, S. S. Turner, P. Day, E. Canadell, S. Firth, R. J. H. Clark, J. Yamada, S. Nakatsuji, Superstructures of donor packing arrangements in a series of molecular charge transfer salts, Chem. Commun., (2004) 18-19.

[37] L. Martin, P. Day, H. Akutsu, J. Yamada, S. Nakatsuji, W. Clegg, R. W. Harrington, P. N. Horton, M. B. Hursthouse, P. McMillan, S. Firth, Metallic molecular crystals containing chiral or racemic guest molecules, CrystEngComm, 9 (2007) 865-867. 
[38] L. V. Zorina, S. S. Khasanov, S. V. Simonov, R. P. Shibaeva, V. N. Zverev, E. Canadell, T. G. Prokhorova, E. B. Yagubskii, Coexistence of two donor packing motifs in the stable molecular metal apseudo-K-(BEDT-TTF) ${ }_{4}\left(\mathrm{H}_{3} \mathrm{O}\right)\left[\mathrm{Fe}\left(\mathrm{C}_{2} \mathrm{O}_{4}\right)_{3}\right] \cdot \mathrm{C}_{6} \mathrm{H}_{4} \mathrm{Br}_{2}$, CrystEngComm, 13 (2011) 2430-2438.

[39] L. Martin, P. Day, P. N. Horton, S. Nakatsuji, J. Yamada, H. Akutsu, Chiral conducting salts of BEDTTTF containing a single enantiomer of tris(oxalato)chromate(III) crystallised from a chiral solvent, J. Mater. Chem., 20 (2010) 2738-2742.

[40] L. Martin, H. Akutsu, P. N. Horton, M. B. Hursthouse, Chirality in charge-transfer salts of BEDT-TTF of tris(oxalato)chromate(III), CrystEngComm, 17 (2015) 2783-2790.

[41] L. Martin, H. Akutsu, P. N. Horton, M. B. Hursthouse, R. W. Harrington, W. Clegg, Chiral RadicalCation Salts of BEDT-TTF Containing a Single Enantiomer of Tris(oxalato)aluminate(III) and chromate(III), Eur. J. Inorg. Chem., 2015 (2015) 1865-1870.

[42] L. Martin, P. Day, S. Nakatsuji, J. Yamada, H. Akutsu, P. Horton, A molecular charge transfer salt of BEDT-TTF containing a single enantiomer of tris(oxalato)chromate(III) crystallised from a chiral solvent, CrystEngComm, 12 (2010) 1369-1372.

[43] L. Martin, H. Engelkamp, H. Akutsu, S. Nakatsuji, J. Yamada, P. Horton, M. B. Hursthouse, Radicalcation salts of BEDT-TTF with lithium tris(oxalato)metallate(III), Dalton Trans., 44 (2015) 6219-6223.

[44] L. Martin, A. L. Morritt, J. R. Lopez, H. Akutsu, Y. Nakazawa, S. Imajo, Y. Ihara, Ambient-pressure molecular superconductor with a superlattice containing layers of tris(oxalato)rhodate enantiomers and 18-crown-6, Inorg. Chem., 56 (2017) 717-720.

[45] L. Martin, A. L. Morritt, J. R. Lopez, H. Akutsu, Y. Nakazawa, S. Imajo, Quasi-Kosterlitz-Thouless molecular superconductor $\beta^{\prime \prime}$-(BEDT-TTF $)_{2}\left[\left(\mathrm{H}_{2} \mathrm{O}\right)\left(\mathrm{NH}_{4}\right)_{2} \mathrm{Cr}\left(\mathrm{C}_{2} \mathrm{O}_{4}\right)_{3}\right]$.18-crown-6, Inorg. Chem., 56 (2017) $14045-14052$.

[46] S. Rashid, S. S. Turner, P. Day, M. E. Light, M. B. Hursthouse, S. Firth, R. J. H. Clark, The first molecular charge transfer salt containing proton channels, Chem. Commun., (2001) 1462-1463.

[47] A. Akutsu-Sato, H. Akutsu, S. S. Turner, P. Day, M. R. Probert, J. A. K. Howard, T. Akutagawa, S. Takeda, T. Nakamura and T. Mori, The First Proton-Conducting Metallic lon-Radical Salts, Angew. Chem., Int. Ed., 44 (2005) 291-295.

[48] B. Zhang, Y. Zhang, F. Liu, Y. Guo, Synthesis, crystal structure, and characterization of chargetransfer salt: (BEDT-TTF) $)_{5}\left[\mathrm{Fe}\left(\mathrm{C}_{2} \mathrm{O}_{4}\right)_{3}\right] \cdot\left(\mathrm{H}_{2} \mathrm{O}\right)_{2} \cdot \mathrm{CH}_{2} \mathrm{Cl}_{2}$ (BEDT-TTF $=$ bis(ethylenedithio)tetrathiafulvalene). CrystEngComm, 11 (2009) 2523-2528.

[49] L. Martin, P. Day, W. Clegg, R. W. Harrington, P. N. Horton, A. Bingham, M. B. Hursthouse, P. McMillan, S. Firth, Multi-layered molecular charge-transfer salts containing alkali metal ions, J. Mater. Chem, 17 (2007) 3324-3329.

[50] L. Martin, P. Day, S. A. Barnett, D. A. Tocher, P. N. Horton, M. B. Hursthouse, Magnetic molecular charge-transfer salts containing layers of water and tris(oxalato)ferrate(III) anions, CrystEngComm, 10 (2008) 192-196.

[51] E. Coronado, J. R. Galán-Mascarós, C. J. Gómez-García, E. Martínez-Ferrero, S. van Smaalen, Incommensurate Nature of the Multilayered Molecular Ferromagnetic Metals Based on 
Bis(ethylenedithio)tetrathiafulvalene and Bimetallic Oxalate Complexes, Inorg. Chem., 43 (2004) 4808-4810.

[52] E. Coronado, A. Forment-Aliaga, J. R. Galán-Mascarós, C. Giménez-Saiz, C. J. Gómez-García, E. Martínez-Ferrero, A. Nuez, F. M. Romero, Multifunctional Molecular Materials, Solid State Sci., 5 (2003) 917.

[53] L. Martin, S. S. Turner, P. Day, P. Guionneau, J. A. K. Howard, M. Uruichi, K. Yakushi, Synthesis, crystal structure and properties of the semiconducting molecular charge-transfer salt (bedt$\mathrm{ttf})_{2} \mathrm{Ge}\left(\mathrm{C}_{2} \mathrm{O}_{4}\right)_{3} \cdot \mathrm{PhCN}$ [bedt-ttf = bis(ethylenedithio)tetrathiafulvalene], J. Mater. Chem., 9 (1999) 27312736.

[54] L. Martin, P. Day, S. Nakatsuji, J. Yamada, H. Akutsu, P. N. Horton, BEDT-TTF Tris(oxalato)germanate(IV) Salts with Novel Donor Packing Motifs, Bull. Chem. Soc. Jpn., 83 (2010) 419-423.

[55] J. Lopez, H. Akutsu, L. Martin, Radical-cation salt with novel BEDT-TTF packing motif containing tris(oxalato)germanate(IV), Synth. Met., 209 (2015) 188-191.

[56] J. M. Kosterlitz, D. J. Thouless, Long range order and metastability in two dimensional solids and superfluids. (Application of dislocation theory), J. Phys. C: Solid State Phys., 5 (1972) L124; J. M. Kosterlitz, D. J. Thouless, Ordering, metastability and phase transitions in two-dimensional systems, J. Phys. C: Solid State Phys., 6 (1973) 1181; J. M. Kosterlitz, The critical properties of the two-dimensional xy model, J. Phys. C: Solid State Phys., 7 (1974) 1046.

[57] G. L. J. A. Rikken, E. Raupach, Observation of magneto-chiral dichroism, Nature, 390 (1997) 493; G. L. J. A. Rikken, J. Folling, P. Wyder, Electrical Magnetochiral Anisotropy, Phys. Rev. Lett., 87 (2001) 236602.

[58] V. Krstic, S. Roth, M. Burghard, K. Kern, G. L. J. A. Rikken, Magneto-chiral anisotropy in charge transport through single-walled carbon nanotubes, J. Chem. Phys., 117 (2002) 11315; V. Krstic, G. L. J. A. Rikken, Magneto-chiral anisotropy of the free electron on a helix, Chem. Phys. Lett., 364 (2002) 51.

[59] C. J. Gómez-García, E. Coronado, S. Curreli, C. Giménez-Saiz, P. Deplano, M. L. Mercuri, L. Pilia, A. Serpe, C. Faulmann, E. Canadell, A chirality-induced alpha phase and a novel molecular magnetic metal in the BEDT-TTF/tris(croconate)ferrate(III) hybrid molecular system, Chem. Commun., (2006) 4931.

[60] A. M. Madalan, E. Canadell, P. Auban-Senzier, D. Brânzea, N. Avarvari, M. Andruh, Conducting mixed-valence salt of bis(ethylenedithio)tetrathiafulvalene (BEDT-TTF) with the paramagnetic heteroleptic anion [Cr'I'(oxalate)2(2,2'-bipyridine)]', New J. Chem., 32 (2008) 333.

[61] E. Coronado, J. R. Galán-Mascarós, C. J. Gómez-García, A. Murcia-Martinez, E. Canadell, A Chiral Molecular Conductor: Synthesis, Structure, and Physical Properties of $[\mathrm{ET}]_{3}\left[\mathrm{Sb}_{2}(\mathrm{~L}-\operatorname{tart})_{2}\right] \cdot \mathrm{CH}_{3} \mathrm{CN}(\mathrm{ET}=$ Bis(ethylendithio)tetrathiafulvalene; L-tart = (2R,3R)-(+)-Tartrate), Inorg. Chem., 43 (2004) 8072.

[62] M. Clemente-León, E. Coronado, C. J. Gómez-García, A. Soriano-Portillo, S. Constant, R. Frantz, J. Lacour, Unusual packing of ET molecules caused by $\pi-\pi$ stacking interactions with TRISPHAT molecules in two [ET][TRISPHAT] salts, Inorg. Chim. Acta, 360 (2007) 955; F. Riobé, F. Piron, C. Réthoré, A. M. Madalan, C. J. Gómez-García, J. Lacour, J. D. Wallis, N. Avarvari, Radical cation salts of BEDT-TTF, 
enantiopure tetramethyl-BEDT-TTF, and TTF-Oxazoline (TTF-Ox) donors with the homoleptic TRISPHAT anion, New J. Chem., 35 (2011) 2279.

[63] J. R. Lopez, L. Martin, J. D. Wallis, H. Akutsu, Y. Nakazawa, J-i. Yamada, T. Kadoya, S. J. Coles, C. Wilson, Enantiopure and racemic radical-cation salts of $\mathrm{B}(\text { malate })_{2}{ }^{-}$anions with BEDT-TTF, Dalton Trans., 45 (2016) 9285.

[64] S. Benmansour, E. Coronado, C. Giménez-Saiz, C. J. Gómez-García, C. Rößer, Metallic Charge-Transfer Salts of Bis(ethylenedithio)tetrathiafulvalene with Paramagnetic Tetrachloro(oxalato)rhenate(IV) and Tris(chloranilato)ferrate(III) Anions, Eur. J. Inorg. Chem., 24 (2014) 3949; M. Atzori, F. Pop, P. Auban-Senzier, C. J. Gómez-García, E. Canadell, F. Artizzu, A. Serpe, P. Deplano, N. Avarvari, M. L. Mercuri, Structural Diversity and Physical Properties of Paramagnetic Molecular Conductors Based on Bis(ethylenedithio)tetrathiafulvalene (BEDT-TTF) and the Tris(chloranilato)ferrate(III) Complex, Inorg. Chem., 53 (2014) 7028.

[65] F. Riobé, N Avarvari, $C_{2}$-symmetric chiral tetrathiafulvalene-bis(oxazolines) (TTF-BOX): new precursors for organic materials and electroactive metal complexes, Chem. Commun., (2009) 3753; J. Lieffrig, R. Le Pennec, O. Jeannin, P. Auban-Senzier, M. Fourmigué, Toward chiral conductors: combining halogen bonding ability and chirality within a single tetrathiafulvalene molecule, CrystEngComm, 15 (2013) 4408; S. Yang, A. C. Brooks, L. Martin, P. Day, H. Li, P. Horton, L. Male, J. D. Wallis, Novel enantiopure bis(pyrrolo)tetrathiafulvalene donors exhibiting chiral crystal packing arrangements, CrystEngComm, 11 (2009) 993; S. Yang, A. C. Brooks, L. Martin, P. Day, M. Pilkington, W. Clegg, R. W. Harrington, L. Russo, J. D. Wallis, New Chiral Organosulfur Donors Related to Bis(ethylenedithio)tetrathiafulvalene, Tetrahedron, 34 (2010) 6977; M. Chas, M. Lemarié, M. Gulea, N. Avarvari, Chemo- and enantioselective sulfoxidation of bis(ethylenedithio)-tetrathiafulvalene (BEDT-TTF) into chiral BEDT-TTF-sulfoxide, Chem. Commun., (2008) 220; S. Yang, F. Pop, C. Melan, A. C. Brooks, L. Martin, P. Horton, P. Auban-Senzier, G. L. J. A. Rikken, N. Avarvari, John D. Wallis, Charge transfer complexes and radical cation salts of chiral methylated organosulfur donors, CrystEngComm, 16 (2014) 3906.

[66] F. Pop, P. Auban-Senzier, E. Canadell, G. L. J. A. Rikken, N. Avarvari, Electrical magnetochiral anisotropy in a bulk chiral molecular conductor, Nat. Commun. 5:3757 doi: 10.1038/ncomms4757 (2014); F. Pop, P. Auban-Senzier, A. Frackowiak, K. Ptaszyński, I. Olejniczak, J. D. Wallis, E. Canadell, N. Avarvari, Chirality Driven Metallic versus Semiconducting Behavior in a Complete Series of Radical Cation Salts Based on Dimethyl-Ethylenedithio-Tetrathiafulvalene (DM-EDT-TTF), J. Am. Chem. Soc., 135 (2013) 17176.

[67] I. Awheda, S. Yang, L. Martin, S. Krivickas, A. C. Brooks, F. Pelletier, P. Day, M. Pilkington, P. Horton, J. D. Wallis, Synthesis of new Organosulfur Donors with Hydrogen Bonding Functionality and their First Charge Transfer Salts, Tetrahedron, 69 (2013) 8738.

[68] M. Atzori, F. Pop, P. Auban-Senzier, R. Clérac, E. Canadell, M. L. Mercuri, N. Avarvari, Complete Series of Chiral Paramagnetic Molecular Conductors Based on Tetramethyl-bis(ethylenedithio)tetrathiafulvalene (TM-BEDT-TTF) and Chloranilate-Bridged Heterobimetallic Honeycomb Layers, Inorg. Chem., 54 (2015) 3643. 


\section{HIGHLIGHTS}

- Multifunctional molecular conductors of BEDT-TTF with tris(oxalato)metallate

- 2017 discovery of molecular superconductor $\beta "$ "-(BEDT-TTF $)_{2}\left[\left(\mathrm{H}_{2} \mathrm{O}\right)\left(\mathrm{NH}_{4}\right)_{2} \mathrm{M}\left(\mathrm{C}_{2} \mathrm{O}_{4}\right)_{3}\right]$.18-crown-6

- Kosterlitz-Thouless transition in 2D superconductor

- Chiral induction in molecular semiconductors

- Combination of ferromagnetism and metallic behaviour

KEYWORDS

Tris(oxalato)metallate, BEDT-TTF, superconductor, metal, semiconductor, Kosterlitz-Thouless 


\section{FIGURE CAPTIONS}

Scheme 1 BEDT-TTF.

Scheme $2(R)-(-)$-carvone

FIG 1 Layered packing of monoclinic $\beta$ " radical-cation salts. Sulphur atoms are yellow, carbon grey, nitrogen blue, oxygen red and hydrogen white. The metal centre atoms are turquoise and halogen atoms are brown.

FIG 2 BEDT-TTF donor layer in monoclinic $\beta$ " radical-cation salts. The two crystallographically independent BEDT-TTF molecules are coloured red (A) and yellow (B) and show the AABBAABB packing arrangement within a stack.

FIG 3 Tris(oxalato)metallate anion layer in monoclinic $\beta$ " radical-cation salts. All tris(oxalato)metallates within a layer are the same enantiomer, this figure shows the $\Delta$ layer. Carbon atoms are grey, nitrogen blue, oxygen red and hydrogen white. The metal centre atoms are turquoise and halogen atoms are brown.

FIG 4 BEDT-TTF donor layer in orthorhombic pseudo-k radical-cation salts. The two crystallographically independent BEDT-TTF molecules are coloured red (BEDT-TTF ${ }^{\circ}$ ) and yellow (BEDT-TTF ${ }^{1+}$ ).

FIG 5 Tris(oxalato)metallate anion layer in orthorhombic pseudo-k radical-cation salts. Within a layer there are alternating rows of tris(oxalato)metallate enantiomers as indicated by $\Delta$ and $\Lambda$. The benzonitrile molecules are orientationally disordered over two positions with the $\mathrm{C} \equiv \mathrm{N}$ group directed towards an $\mathrm{NH}_{4}{ }^{+} / \mathrm{H}_{3} \mathrm{O}^{+}$cation. Metal atoms are turquoise, carbon grey, nitrogen blue, oxygen red and hydrogen white.

FIG 6 Layered packing of triclinic $\alpha-\beta$ " radical-cation salts. Sulphur atoms are yellow, carbon grey, nitrogen blue, oxygen red, hydrogen white and the metal centre orange. The position of the phenyl group of the unsymmetrical solvent molecule within the anion layer is indicated with an arrow.

FIG 7 BEDT-TTF a packing in bilayered triclinic radical-cation salts. The two crystallographically independent BEDT-TTF molecules are coloured red and yellow.

FIG 8 3:1 Tris(oxalato)metallate anion layer in 3:1 salts (BEDT-TTF) ${ }_{3}\left[\mathrm{NaCr}\left(\mathrm{C}_{2} \mathrm{O}_{4}\right)_{3}\right] \cdot$ nitromethane $P 2{ }_{1} 2_{1} 2_{1}$ (a), $P 2_{1}$ (b), and (BEDT-TTF) ${ }_{3}\left[\mathrm{NaCr}\left(\mathrm{C}_{2} \mathrm{O}_{4}\right)_{3}\right] \cdot$ ethanol P1 (c). The nitromethane molecule in (a) and the ethanol molecule in (c) are disordered over two positions. $\mathrm{Na}$ and $\mathrm{Cr}$ atoms are disordered on the same sites in (a). $\mathrm{Cr}$ atoms are blue and $\mathrm{Na}$ atoms are purple in (b) and (c). Carbon atoms are grey, nitrogen blue, oxygen red and hydrogen white.

FIG 9 BEDT-TTF packing in 3:1 salts (BEDT-TTF) ${ }_{3}\left[(A) M\left(C_{2} O_{4}\right)_{3}\right] \cdot$ solvent $-P 2{ }_{1} 2_{1} 2_{1}(a), P 2_{1}$ (b), $P 1$ (c), and $\theta$ (d). Sulphur atoms are yellow, carbon grey and hydrogen white.

FIG 10 Layered packing of 2:1 superconductor $\beta^{\prime \prime}$-(BEDT-TTF $)_{2}\left[\left(\mathrm{H}_{2} \mathrm{O}\right)\left(\mathrm{NH}_{4}\right)_{2} \mathrm{M}\left(\mathrm{C}_{2} \mathrm{O}_{4}\right)_{3}\right] \cdot 18$-crown-6, $\mathrm{M}=$ $\mathrm{Cr}^{3+}(\mathrm{Tc}=4.0-4.9 \mathrm{~K})$ or $\mathrm{M}=\mathrm{Rh}^{3+}(\mathrm{Tc}=2.7 \mathrm{~K})$.[44,45] Sulphur atoms are yellow, carbon grey, nitrogen blue, oxygen red, hydrogen white and metal centre turquoise.

FIG 11 Layered packing of proton conductor $\beta "$ "-(BEDT-TTF $)_{4}\left[(\mathrm{~A}) \mathrm{M}\left(\mathrm{C}_{2} \mathrm{O}_{4}\right)_{3}\right]_{2} \cdot\left[(\mathrm{A})_{2} \text { 18-crown-6](} \mathrm{H}_{2} \mathrm{O}\right)_{5}$ (M $=\mathrm{Cr}$ or $\mathrm{Ga}$, Cat $=\mathrm{NH}_{4}{ }^{+}$or $\left.\mathrm{H}_{3} \mathrm{O}^{+}\right)$. [46,47] Sulphur atoms are yellow, carbon grey, oxygen red, hydrogen white and metal centre is blue. 
FIG 12 Tris(oxalato)metallate anion layers of $\beta^{\prime}-(\mathrm{BEDT}-\mathrm{TTF})_{5}\left[\mathrm{Fe}\left(\mathrm{C}_{2} \mathrm{O}_{4}\right)_{3}\right] \cdot\left(\mathrm{H}_{2} \mathrm{O}\right)_{2} \cdot \mathrm{CH}_{2} \mathrm{Cl}_{2}[48]$ (a) and $\alpha$ $(\mathrm{BEDT}-\mathrm{TTF})_{12}\left[\mathrm{Fe}\left(\mathrm{C}_{2} \mathrm{O}_{4}\right)_{3}\right]_{2} \cdot\left(\mathrm{H}_{2} \mathrm{O}\right)_{n}[50]$ (b). Dichloromethane molecules in (a) are disordered over two positions. Water molecules are represented by red spheres in (b). Carbon atoms are grey, oxygen red, hydrogen white and chlorine green.

FIG 13 BEDT-TTF layer (a) and tris(oxalato)metallate anion layer (b) of $\eta$-(BEDT-

$\mathrm{TTF})_{4}\left(\mathrm{H}_{2} \mathrm{O}\right)$ LiFe $\left(\mathrm{C}_{2} \mathrm{O}_{4}\right)_{3}$ [43]. Sulphur atoms are yellow, carbon grey, oxygen red, hydrogen white, lithium pink and iron orange. The hexagonal cavity in this salt contains heavily disordered dichloromethane which could not be resolved.

FIG 14 Layered packing of a'"--(BEDT-TTF) ${ }_{9}\left[\mathrm{M}\left(\mathrm{C}_{2} \mathrm{O}_{4}\right)_{3}\right]_{8} \mathrm{Na}_{18}\left(\mathrm{H}_{2} \mathrm{O}\right)_{24}[42,49]$. Sulphur atoms are yellow, carbon grey, oxygen red, hydrogen white, sodium purple and the metal centre orange.

FIG 15 Layered packing of $a$-(BEDT-TTF) ${ }_{10}(18 \text {-crown-6 })_{6} \mathrm{~K}_{6}\left[\mathrm{Fe}\left(\mathrm{C}_{2} \mathrm{O}_{4}\right)_{3}\right]_{4}\left(\mathrm{H}_{2} \mathrm{O}\right)_{24}[49]$. Sulphur atoms are yellow, carbon grey, oxygen red, hydrogen white, potassium purple, and iron orange.

FIG 16 Checkerboard donor-anion layer with interleaved benzonitrile layers in (BEDTTTF $)_{2}\left[\mathrm{Ge}\left(\mathrm{C}_{2} \mathrm{O}_{4}\right)_{3}\right]$.PhCN[53] (a), and checkerboard layer in (BEDT-TTF) $)_{5}\left[\mathrm{Ge}\left(\mathrm{C}_{2} \mathrm{O}_{4}\right)_{3}\right]_{2}[54]$ (b). Sulphur atoms are yellow, carbon grey, oxygen red, hydrogen white, nitrogen blue, and germanium turquoise.

FIG 17 Tris(oxalato)metallate anion layers of (BEDT-TTF) 7 [ $\left.\mathrm{Ge}\left(\mathrm{C}_{2} \mathrm{O}_{4}\right)_{3}\right]_{2}\left(\mathrm{CH}_{2} \mathrm{Cl}_{2}\right)_{0.87}\left(\mathrm{H}_{2} \mathrm{O}\right)_{0.09}$, [54] (a) and (BEDT-TTF) ${ }_{4} \mathrm{Ge}\left(\mathrm{C}_{2} \mathrm{O}_{4}\right)_{3} \cdot\left(\mathrm{CH}_{2} \mathrm{Cl}_{2}\right)_{0.50}$.[55] (b). Dichloromethane molecules are disordered over two positions. Carbon atoms are grey, oxygen red, hydrogen white, chlorine green, and germanium turquoise. 
Table $14: 1$ radical cation-salts of BEDT-TTF with tris(oxalato)ferrate(III) and their conducting properties. Salts all have the BEDT-TTF donor packing motif $\beta$ " and have the formula $\beta$ "-(BEDT$\mathrm{TTF})_{4}\left[(\mathrm{~A}) \mathrm{Fe}\left(\mathrm{C}_{2} \mathrm{O}_{4}\right)_{3}\right] \cdot$ solvent. All salts crystallise in the monoclinic space group $\mathrm{C2} / \mathrm{c}$. $\mathrm{Ph}=\mathrm{Phenyl}, \mathrm{Py}=$ pyridine/pyridyl.

\begin{tabular}{|l|l|l|l|l|}
\hline $\mathrm{M}^{3+}$ & $\mathrm{A}^{+}$ & Solvent & $\begin{array}{l}\text { Conducting } \\
\text { Properties }\end{array}$ & Reference \\
\hline $\mathrm{Fe}$ & $\mathrm{H}_{3} \mathrm{O}^{+}$ & $\mathrm{PhCN}$ & $T_{\mathrm{c}}=7.0-8.5 \mathrm{~K}$ & {$[5,8,9,10,11]$} \\
\hline $\mathrm{Fe}$ & $\mathrm{H}_{3} \mathrm{O}^{+} / \mathrm{NH}_{4}^{+}$ & $\mathrm{PhNO}_{2}$ & $T_{\mathrm{c}}=6.2 \mathrm{~K}$ & {$[12,13,14]$} \\
\hline $\mathrm{Fe}$ & $\mathrm{H}_{3} \mathrm{O}^{+}$ & $2-\mathrm{BrPy}$ & $\mathrm{T}_{\mathrm{c}}=4.3 \mathrm{~K}$ & {$[15]$} \\
\hline $\mathrm{Fe}$ & $\mathrm{H}_{3} \mathrm{O}^{+}$ & $\mathrm{PhBr}$ & $\mathrm{T}_{\mathrm{c}}=4 \mathrm{~K}$ & {$[16]$} \\
\hline $\mathrm{Fe}$ & $\mathrm{H}_{3} \mathrm{O}^{+}$ & $2-\mathrm{ClPy}$ & $T_{\mathrm{c}}=2.4-4.0 \mathrm{~K}$ & {$[15]$} \\
\hline $\mathrm{Fe}$ & $\mathrm{H}_{3} \mathrm{O}^{+}$ & $\mathrm{PhF}$ & $T_{\mathrm{c}}=<1 \mathrm{~K}$ & {$[11,17,18]$} \\
\hline $\mathrm{Fe}$ & $\mathrm{H}_{3} \mathrm{O}^{+}$ & $\mathrm{PhCl}$ & Metal $>0.4 \mathrm{~K}$ & {$[11,17-20]$} \\
\hline $\mathrm{Fe}$ & $\mathrm{H}_{3} \mathrm{O}^{+}$ & $3-\mathrm{ClPy}$ & Metal $>0.4 \mathrm{~K}$ & {$[15]$} \\
\hline $\mathrm{Fe}$ & $\mathrm{H}_{3} \mathrm{O}^{+}$ & $3-\mathrm{BrPy}$ & Metal $>0.4 \mathrm{~K}$ & {$[15]$} \\
\hline $\mathrm{Fe}$ & $\mathrm{H}_{3} \mathrm{O}^{+}$ & $1,2-\mathrm{Cl}{ }_{2} \mathrm{Ph}$ & Metal $>0.4 \mathrm{~K}$ & {$[11,21]$} \\
\hline $\mathrm{Fe}$ & $\mathrm{NH}_{4}^{+}$ & $(\mathrm{CH})_{2} \mathrm{NC}(\mathrm{O}) \mathrm{H}$ & Metal $>4.2 \mathrm{~K}$ & {$[22]$} \\
\hline $\mathrm{Fe}$ & $\mathrm{Rb}^{+}$ & $\mathrm{Py}$ & Metal $>2 \mathrm{~K}$ & {$[19]$} \\
\hline $\mathrm{Fe}$ & $\mathrm{H}_{3} \mathrm{O}^{+}$ & $\mathrm{Py}$ & $T_{\mathrm{Ml}}=116 \mathrm{~K}$ & {$[10,23,24]$} \\
\hline $\mathrm{Fe}$ & $\mathrm{K}^{+}$ & $\mathrm{Phl}$ & $E_{\mathrm{a}}=64$ meV & {$[18]$} \\
\hline $\mathrm{Fe}$ & $\mathrm{K}^{+}$ & $\mathrm{PhCl}$ & Semiconductor & {$[25]$} \\
\hline
\end{tabular}


Table 2 4:1 radical cation-salts of BEDT-TTF with tris(oxalato)metallate(III) and their conducting properties. Salts all have the BEDT-TTF donor packing motif $\beta$ " and have the formula $\beta$ "-(BEDT$\operatorname{TTF})_{4}\left[(\mathrm{~A}) \mathrm{M}\left(\mathrm{C}_{2} \mathrm{O}_{4}\right)_{3}\right]$.solvent. All salts crystallise in the monoclinic space group $\mathrm{C} 2 / \mathrm{C}$. $\mathrm{Ph}=\mathrm{Phenyl}, \mathrm{Py}=$ pyridine/pyridyl.

\begin{tabular}{|l|l|l|l|l|}
\hline $\mathrm{M}^{3+}$ & $\mathrm{A}^{+}$ & Solvent & Conducting Properties & Reference \\
\hline $\mathrm{Ga}$ & $\mathrm{H}_{3} \mathrm{O}^{+}$ & $\mathrm{PhNO}_{2}$ & $T_{\mathrm{C}}=7.5 \mathrm{~K}$ & {$[26,27]$} \\
\hline $\mathrm{Ga}$ & $\mathrm{H}_{3} \mathrm{O}^{+}$ & $\mathrm{Py}$ & $T_{\mathrm{C}}=1.5 \mathrm{~K}$ & {$[26,27]$} \\
\hline $\mathrm{Ga}$ & $\mathrm{H}_{3} \mathrm{O}^{+} / \mathrm{K}^{+}$ & $\mathrm{PhBr}$ & Metal $>0.5 \mathrm{~K}$ & {$[28]$} \\
\hline $\mathrm{Ga}$ & $\mathrm{H}_{3} \mathrm{O}^{+} / \mathrm{K}^{+}$ & $2-\mathrm{ClPy}$ & Metal $>0.5 \mathrm{~K}$ & {$[29]$} \\
\hline $\mathrm{Ga}$ & $\mathrm{H}_{3} \mathrm{O}^{+} / \mathrm{K}^{+}$ & $2-\mathrm{BrPy}$ & Metal $>0.5 \mathrm{~K}$ & {$[29]$} \\
\hline $\mathrm{Cr}$ & $\mathrm{H}_{3} \mathrm{O}^{+}$ & $\mathrm{PhCN}$ & $T_{\mathrm{c}}=5.5-6.0 \mathrm{~K}$ & {$[9,30,31]$} \\
\hline $\mathrm{Cr}$ & $\mathrm{H}_{3} \mathrm{O}^{+} / \mathrm{NH}_{4}^{+}$ & $\mathrm{PhNO}{ }_{2}$ & $T_{\mathrm{c}}=5.8 \mathrm{~K}$ & {$[12]$} \\
\hline $\mathrm{Cr}$ & $\mathrm{H}_{3} \mathrm{O}^{+}$ & $\mathrm{PhBr}$ & $T_{\mathrm{c}}=1.5 \mathrm{~K}$ & {$[20]$} \\
\hline $\mathrm{Cr}$ & $\mathrm{NH}_{4}^{+}$ & $\left(\mathrm{CH}_{3}\right)_{2} \mathrm{NC}(\mathrm{O}) \mathrm{H}$ & Metal $>4.2 \mathrm{~K}$ & {$[22]$} \\
\hline $\mathrm{Cr}$ & $\mathrm{K}^{+} / \mathrm{NH}_{4}^{+}$ & $(\mathrm{CH})_{2} \mathrm{NC}(\mathrm{O}) \mathrm{H}$ & Metal $>4.2 \mathrm{~K}$ & {$[22]$} \\
\hline $\mathrm{Cr}$ & $\mathrm{H}_{3} \mathrm{O}^{+}$ & $\mathrm{PhCl}$ & Metal $>130 \mathrm{~K}$ & {$[20]$} \\
\hline $\mathrm{Cr}$ & $\mathrm{H}_{3} \mathrm{O}^{+}$ & $\mathrm{CH}$ & {$[32$} \\
\hline $\mathrm{Cr}$ & $\mathrm{H}_{3} \mathrm{O}^{+}$ & $\mathrm{Py}$ & $T_{\text {Metal-semiconductor }}=150 \mathrm{~K}$ & {$[24]$} \\
\hline $\mathrm{Cr}$ & $\mathrm{H}_{3} \mathrm{O}^{+} / \mathrm{K}^{+}$ & $2-\mathrm{ClPy}$ & Metal $>0.5 \mathrm{~K}$ & {$[29]$} \\
\hline $\mathrm{Cr}$ & $\mathrm{H}_{3} \mathrm{O}^{+} / \mathrm{K}^{+}$ & $2-\mathrm{BrPy}$ & Metal $>0.5 \mathrm{~K}$ & {$[29]$} \\
\hline $\mathrm{Rh}$ & $\mathrm{NH}_{4}^{+}$ & $\mathrm{PhBr}$ & Metal $>0.5 \mathrm{~K}$ & {$[33]$} \\
\hline $\mathrm{Rh}$ & $\mathrm{H}_{3} \mathrm{O}^{+}$ & $\mathrm{PhCl}$ & $T_{\mathrm{c}}=2.5 \mathrm{~K}$ & {$[33]$} \\
\hline $\mathrm{Rh}$ & $\mathrm{H}_{3} \mathrm{O}^{+}$ & $\mathrm{PhF}$ & Metal $>0.8 \mathrm{~K}$ & {$[33]$} \\
\hline $\mathrm{Ru}$ & $\mathrm{H}_{3} \mathrm{O}^{+} / \mathrm{K}^{+}$ & $\mathrm{PhBr}$ & $T_{\mathrm{C}}=2.8-6.3 \mathrm{~K}$ & {$[34]$} \\
\hline $\mathrm{Mn}$ & $\mathrm{H}_{3} \mathrm{O}^{+}$ & $\mathrm{PhBr}$ & $T_{\mathrm{c}}=2 \mathrm{~K}$ & {$[18]$} \\
\hline & & & \\
\hline
\end{tabular}


Table 3 4:1 radical cation-salts of BEDT-TTF with tris(oxalato)ferrate(III) which include a solvent mixture and their conducting properties. Salts have the formula (BEDT-TTF) ${ }_{4}\left[(A) M\left(C_{2} \mathrm{O}_{4}\right)_{3}\right] \cdot$ solvent. $\mathrm{Ph}=$ Phenyl, Py = pyridine. $\rho T_{\mathrm{c}}$ is Tc measured by transport, $\chi T_{c}$ is Tc measured by SQUID magnetometry

\begin{tabular}{|c|c|c|c|c|c|c|}
\hline $\mathrm{M}^{3+}$ & $\mathrm{A}^{+}$ & Solvent & $\begin{array}{l}\text { BEDT-TTF } \\
\text { packing }\end{array}$ & $\begin{array}{l}\text { Space } \\
\text { Group }\end{array}$ & Conducting Properties & Reference \\
\hline $\mathrm{Fe}$ & $\mathrm{H}_{3} \mathrm{O}^{+}$ & $(\mathrm{PhCN})_{0.22}(\mathrm{Py})_{0.78}$ & $\beta^{\prime \prime}$ & $\mathrm{C} 2 / \mathrm{c}$ & $\rho T_{\mathrm{c}}=3.9 \mathrm{~K}, \chi T_{\mathrm{c}}=? \mathrm{~K}$ & [10] \\
\hline $\mathrm{Fe}$ & $\mathrm{H}_{3} \mathrm{O}^{+}$ & $(\mathrm{PhCN})_{0.23}(\mathrm{Py})_{0.77}$ & $\beta^{\prime \prime}$ & $C 2 / c$ & $\rho T_{\mathrm{c}}=? \mathrm{~K}, \chi T_{\mathrm{c}}=? \mathrm{~K}$ & [10] \\
\hline $\mathrm{Fe}$ & $\mathrm{H}_{3} \mathrm{O}^{+}$ & $(\mathrm{PhCN})_{0.34}(\mathrm{Py})_{0.66}$ & $\beta^{\prime \prime}$ & $C 2 / c$ & $\rho T_{\mathrm{c}}=? \mathrm{~K}, \chi T_{\mathrm{c}}=5.8 \mathrm{~K}$ & [10] \\
\hline $\mathrm{Fe}$ & $\mathrm{H}_{3} \mathrm{O}^{+}$ & $(\mathrm{PhCN})_{0.38}(\mathrm{Py})_{0.62}$ & $\beta^{\prime \prime}$ & $C 2 / c$ & $\rho T_{\mathrm{c}}=6.9 \mathrm{~K}, \chi T_{\mathrm{c}}=? \mathrm{~K}$ & [10] \\
\hline $\mathrm{Fe}$ & $\mathrm{H}_{3} \mathrm{O}^{+}$ & $(\mathrm{PhCN})_{0.43}(\mathrm{Py})_{0.57}$ & $\beta^{\prime \prime}$ & $C 2 / c$ & $\rho T_{\mathrm{c}}=6.7 \mathrm{~K}, \chi T_{\mathrm{c}}=? \mathrm{~K}$ & [10] \\
\hline $\mathrm{Fe}$ & $\mathrm{H}_{3} \mathrm{O}^{+}$ & $(\mathrm{PhCN})_{0.54}(\mathrm{Py})_{0.46}$ & $\beta^{\prime \prime}$ & $C 2 / c$ & $\rho T_{\mathrm{c}}=5.9 \mathrm{~K}, \chi T_{\mathrm{c}}=6.8 \mathrm{~K}$ & [10] \\
\hline $\mathrm{Fe}$ & $\mathrm{H}_{3} \mathrm{O}^{+}$ & $(\mathrm{PhCN})_{0.61}(\mathrm{Py})_{0.39}$ & $\beta^{\prime \prime}$ & $C 2 / c$ & $\rho T_{\mathrm{c}}=4.2 \mathrm{~K}, \chi T_{\mathrm{c}}=6.1 \mathrm{~K}$ & [10] \\
\hline $\mathrm{Fe}$ & $\mathrm{H}_{3} \mathrm{O}^{+}$ & $(\mathrm{PhCN})_{0.90}(\mathrm{Py})_{0.10}$ & $\beta^{\prime \prime}$ & $C 2 / c$ & $\rho T_{\mathrm{c}}=? \mathrm{~K}, \chi T_{\mathrm{c}}=7.3 \mathrm{~K}$ & [10] \\
\hline $\mathrm{Fe}$ & $\mathrm{H}_{3} \mathrm{O}^{+}$ & $\mathrm{PhF/PhCN}$ & pseudo-к & Pbcn & Semiconductor & {$[11,17]$} \\
\hline $\mathrm{Fe}$ & $\mathrm{H}_{3} \mathrm{O}^{+}$ & $(\mathrm{PhCN})_{0.17}(\mathrm{PhBr})_{0.83}$ & $\beta^{\prime \prime}$ & $C 2 / c$ & $T_{\mathrm{c}}=4.2 \mathrm{~K}$ & {$[11,17]$} \\
\hline $\mathrm{Fe}$ & $\mathrm{H}_{3} \mathrm{O}^{+}$ & $(\mathrm{PhCN})_{0.86}\left(1,2-\mathrm{Cl}_{2} \mathrm{Ph}\right)_{0.14}$ & $\beta^{\prime \prime}$ & $C 2 / c$ & $T_{c}=7.2 \mathrm{~K}$ & {$[11,17]$} \\
\hline $\mathrm{Fe}$ & $\mathrm{H}_{3} \mathrm{O}^{+}$ & $(\mathrm{PhCN})_{0.88}\left(1,2-\mathrm{Cl}_{2} \mathrm{Ph}\right)_{0.12}$ & pseudo-к & Pbcn & Semiconductor & {$[11,17]$} \\
\hline $\mathrm{Fe}$ & $\mathrm{H}_{3} \mathrm{O}^{+}$ & $(\mathrm{PhCN})_{0.8}\left(\mathrm{PhNO}_{2}\right)_{0.2}$ & $\beta^{\prime \prime}$ & $\mathrm{C} 2 / \mathrm{c}$ & $T_{c}=6.6 \mathrm{~K}$ & {$[11,17]$} \\
\hline $\mathrm{Fe}$ & $\mathrm{H}_{3} \mathrm{O}^{+}$ & $(\mathrm{PhCN})_{0.8}\left(\mathrm{PhNO}_{2}\right)_{0.2}$ & pseudo-k & Pbcn & Semiconductor & {$[11,17]$} \\
\hline $\mathrm{Fe}$ & $\mathrm{H}_{3} \mathrm{O}^{+}$ & $(\mathrm{PhCN})_{0.40}(\mathrm{PhF})_{0.60}$ & $\beta^{\prime \prime}$ & $\mathrm{C} 2 / \mathrm{c}$ & $T_{c}=6.0 \mathrm{~K}$ & {$[11,17]$} \\
\hline $\mathrm{Fe}$ & $\mathrm{H}_{3} \mathrm{O}^{+}$ & $(\mathrm{PhCN})_{0.35}(\mathrm{PhCl})_{0.65}$ & $\beta^{\prime \prime}$ & $\mathrm{C} 2 / \mathrm{c}$ & $T_{c}=6.0 \mathrm{~K}$ & {$[11,17]$} \\
\hline
\end{tabular}


Table 4 4:1 radical cation-salts of BEDT-TTF with tris(oxalato)metallate(III) and their conducting properties. Salts all have the BEDT-TTF donor packing motif pseudo-k and have the formula pseudoк-(BEDT-TTF $)_{4}\left[(\mathrm{~A}) \mathrm{M}\left(\mathrm{C}_{2} \mathrm{O}_{4}\right)_{3}\right]$.benzonitrile. All salts crystallise in the orthorhombic space group Pbcn. $\mathrm{Ph}=\mathrm{Phenyl}$.

\begin{tabular}{|l|l|l|l|l|}
\hline $\mathrm{M}^{3+}$ & $\mathrm{A}^{+}$ & Solvent & $\begin{array}{l}\text { Conducting } \\
\text { Properties }\end{array}$ & Reference \\
\hline $\mathrm{Fe}$ & $\mathrm{NH}_{4}^{+}$ & $\mathrm{PhCN}$ & $E_{\mathrm{a}}=140 \mathrm{meV}$ & {$[8,9]$} \\
\hline $\mathrm{Fe}$ & $\mathrm{K}^{+}$ & $\mathrm{PhCN}$ & $\mathrm{E}_{\mathrm{a}}=141 \mathrm{meV}$ & {$[8]$} \\
\hline $\mathrm{Cr}$ & $\mathrm{H}_{3} \mathrm{O}^{+}$ & $\mathrm{PhCN}$ & $E_{\mathrm{a}}=153 \mathrm{meV}$ & {$[9,31]$} \\
\hline $\mathrm{Al}$ & $\mathrm{NH}_{4}^{+}$ & $\mathrm{PhCN}$ & $E_{\mathrm{a}}=222 \mathrm{meV}$ & {$[9]$} \\
\hline $\mathrm{Co}$ & $\mathrm{NH}_{4}^{+}$ & $\mathrm{PhCN}$ & $E_{\mathrm{a}}=225 \mathrm{meV}$ & {$[9]$} \\
\hline $\mathrm{Rh}$ & $\mathrm{H}_{3} \mathrm{O}^{+}$ & $\mathrm{PhCN}$ & $\mathrm{E}_{\mathrm{a}}=245 \mathrm{meV}$ & {$[33]$} \\
\hline $\mathrm{Ru}$ & $\mathrm{H}_{3} \mathrm{O}^{+} / \mathrm{K}^{+}$ & $\mathrm{PhCN}$ & Semiconductor & {$[34]$} \\
\hline $\mathrm{Mn}$ & $\mathrm{K}^{+}$ & $\mathrm{PhCN}$ & $E_{\mathrm{a}}=180 \mathrm{meV}$ & {$[35]$} \\
\hline
\end{tabular}


Table 5 4:1 radical cation-salts of BEDT-TTF with tris(oxalato)metallate(III) having two BEDT-TTF packing motifs and their conducting properties. Salts all have the BEDT-TTF donor packing motif pseudo-K and have the formula (BEDT-TTF $)_{4}\left[(\mathrm{~A}) \mathrm{M}\left(\mathrm{C}_{2} \mathrm{O}_{4}\right)_{3}\right] \cdot$ solvent. All salts crystallise in the triclinic space group $P$-1. $\mathrm{Ph}=$ Phenyl.

\begin{tabular}{|l|l|l|l|l|l|l|}
\hline $\mathrm{M}^{3+}$ & $\mathrm{A}^{+}$ & Solvent & $\begin{array}{l}\text { BEDT-TTF } \\
\text { packing }\end{array}$ & $\begin{array}{l}\text { Space } \\
\text { Group }\end{array}$ & Conducting Properties & Reference \\
\hline $\mathrm{Fe}$ & $\mathrm{NH}_{4}^{+}$ & $\mathrm{PhCOCH}$ & $\alpha+\beta^{\prime \prime}$ & $P-1$ & $\begin{array}{l}\text { Non-metallic and no } \\
\text { superconductivity }>2 \mathrm{~K}\end{array}$ & {$[36]$} \\
\hline $\mathrm{Fe}$ & $\mathrm{NH}_{4}^{+}$ & $(R / S)-\mathrm{PhCH}(\mathrm{OH}) \mathrm{CH}_{3}$ & $\alpha+\beta^{\prime \prime}$ & $P-1$ & $T_{\mathrm{Ml}}=170 \mathrm{~K}$ & {$[37]$} \\
\hline $\mathrm{Fe}$ & $\mathrm{NH}_{4}^{+}$ & $(\mathrm{S})-\mathrm{PhCH}(\mathrm{OH}) \mathrm{CH}_{3}$ & $\alpha+\beta^{\prime \prime}$ & $P 1$ & $T_{\mathrm{Ml}}=150 \mathrm{~K}$ & {$[37]$} \\
\hline $\mathrm{Fe}$ & $\mathrm{H}_{3} \mathrm{O}^{+}$ & $1,2-\mathrm{Br}_{2} \mathrm{Ph}$ & $\alpha+$ pseudo-K & $P-1$ & Metal $>0.4 \mathrm{~K}$ & {$[11,38]$} \\
\hline $\mathrm{Ga}$ & $\mathrm{H}_{3} \mathrm{O}^{+} / \mathrm{K}^{+}$ & $1,2-\mathrm{Br}_{2} \mathrm{Ph}$ & $\alpha+$ pseudo-K & $P-1$ & Metal $>0.4 \mathrm{~K}$ & {$[28]$} \\
\hline $\mathrm{Ga}$ & $\mathrm{NH}_{4}^{+}$ & $\mathrm{PhN}\left(\mathrm{CH}_{3}\right) \mathrm{CHO}$ & $\alpha+\beta^{\prime \prime}$ & $P-1$ & $\begin{array}{l}\text { Non-metallic and no } \\
\text { superconductivity }>2 \mathrm{~K}\end{array}$ & {$[36]$} \\
\hline $\mathrm{Ga}$ & $\mathrm{NH}_{4}^{+}$ & $\mathrm{PhCH}_{2} \mathrm{CN}$ & $\alpha+\beta^{\prime \prime}$ & $P-1$ & $\begin{array}{l}\text { Non-metallic and no } \\
\text { superconductivity }>2 \mathrm{~K}\end{array}$ & {$[36]$} \\
\hline
\end{tabular}


Table 6 3:1 radical cation-salts of BEDT-TTF with tris(oxalato)metallate(III) and their conducting properties. Salts all have the formula (BEDT-TTF $)_{3}\left[(A) M\left(C_{2} \mathrm{O}_{4}\right)_{3}\right] \cdot$ solvent.

\begin{tabular}{|c|c|c|c|c|c|c|}
\hline $\mathrm{M}^{3+}$ & $\mathrm{A}^{+}$ & Solvent & $\begin{array}{l}\text { BEDT-TTF } \\
\text { packing }\end{array}$ & $\begin{array}{l}\text { Space } \\
\text { Group }\end{array}$ & $\begin{array}{l}\text { Conducting } \\
\text { Properties }\end{array}$ & Reference \\
\hline $\mathrm{Cr}$ & $\mathrm{Na}^{+}$ & $\mathrm{CH}_{3} \mathrm{NO}_{2}$ & $\begin{array}{l}2 \text { parallel } \& 1 \\
\text { perpendicular }\end{array}$ & $P 2{ }_{1}{ }_{1}{ }_{2}{ }_{1}$ & $\begin{array}{l}E_{\mathrm{a}}=80 \\
\mathrm{meV}\end{array}$ & [39] \\
\hline $\mathrm{Cr}$ & $\mathrm{NH}_{4}^{+}$ & $\mathrm{CH}_{3} \mathrm{NO}_{2}$ & $\begin{array}{l}2 \text { parallel \& } 1 \\
\text { perpendicular }\end{array}$ & $P 2{ }_{1}{ }_{1}{ }_{1}$ & $\begin{array}{l}E_{\mathrm{a}}=80 \\
\mathrm{meV}\end{array}$ & [41] \\
\hline $\mathrm{Cr}$ & $\mathrm{Na}^{+}$ & $\mathrm{CH}_{3} \mathrm{NO}_{2}$ & $\begin{array}{l}2 \text { parallel } \& 1 \\
\text { perpendicular }\end{array}$ & $P 2_{1}$ & $\begin{array}{l}E_{\mathrm{a}}=79 \\
\mathrm{meV}\end{array}$ & [39] \\
\hline $\mathrm{Cr}$ & $\mathrm{Na}^{+}$ & $\mathrm{CH}_{3} \mathrm{CN}$ & $\begin{array}{l}2 \text { parallel \& } 1 \\
\text { perpendicular }\end{array}$ & $P 2_{1}$ & $\begin{array}{l}E_{\mathrm{a}}=79 \\
\mathrm{meV}\end{array}$ & [40] \\
\hline Al & $\mathrm{Na}^{+}$ & $\mathrm{CH}_{3} \mathrm{NO}_{2}$ & $\begin{array}{l}2 \text { parallel \& } 1 \\
\text { perpendicular }\end{array}$ & $P 2_{1}$ & $\begin{array}{l}E_{a} \approx 140 \\
\mathrm{meV}\end{array}$ & [41] \\
\hline $\mathrm{Cr}$ & $\mathrm{Na}^{+}$ & $\mathrm{CH}_{2} \mathrm{Cl}_{2}$ & $\begin{array}{l}2 \text { parallel \& } 1 \\
\text { perpendicular }\end{array}$ & $P 1$ & $\begin{array}{l}E_{\mathrm{a}}=69 \\
\mathrm{meV}\end{array}$ & [42] \\
\hline $\mathrm{Cr}$ & $\mathrm{Na}^{+}$ & $\left(\mathrm{CH}_{3}\right)_{2} \mathrm{NC}(\mathrm{O}) \mathrm{H}$ & $\theta$ & $P 1$ & $\begin{array}{l}E_{\mathrm{a}}=43 \\
\mathrm{meV}\end{array}$ & [40] \\
\hline $\mathrm{Cr}$ & $\mathrm{Na}^{+}$ & $\mathrm{EtOH}$ & $\begin{array}{l}2 \text { parallel \& } 1 \\
\text { perpendicular }\end{array}$ & $P 1$ & - & [40] \\
\hline $\mathrm{Cr}$ & $\mathrm{Li}^{+}$ & $\mathrm{EtOH}$ & $\begin{array}{l}2 \text { parallel \& } 1 \\
\text { perpendicular }\end{array}$ & $P 2_{1} / c$ & $\begin{array}{l}E_{a}=179 \\
m e V\end{array}$ & [43] \\
\hline $\mathrm{Fe}$ & $\mathrm{Li}^{+}$ & $\mathrm{EtOH}$ & $\begin{array}{l}2 \text { parallel \& } 1 \\
\text { perpendicular }\end{array}$ & $P 2_{1} / c$ & $\begin{array}{l}E_{a}=126 \\
m e V\end{array}$ & [43] \\
\hline
\end{tabular}


Table 7 2:1 radical cation-salts of BEDT-TTF with tris(oxalato)metallate(III) incorporating 18-crown-6 ether into the lattice and their conducting properties.

\begin{tabular}{|c|c|c|c|}
\hline Formula & $\begin{array}{l}\text { Space } \\
\text { Group }\end{array}$ & $\begin{array}{l}\text { Conducting } \\
\text { Properties }\end{array}$ & Reference \\
\hline$\beta^{\prime \prime}$-(BEDT-TTF $)_{2}\left[\left(\mathrm{H}_{2} \mathrm{O}\right)\left(\mathrm{NH}_{4}\right)_{2} \mathrm{Rh}\left(\mathrm{C}_{2} \mathrm{O}_{4}\right)_{3}\right] \cdot$ 18-crown-6 & $P-1$ & $T_{\mathrm{c}}=2.7 \mathrm{~K}$ & [44] \\
\hline$\beta^{\prime \prime}-(\mathrm{BEDT}-\mathrm{TTF})_{2}\left[\left(\mathrm{H}_{2} \mathrm{O}\right)\left(\mathrm{NH}_{4}\right)_{2} \mathrm{Cr}\left(\mathrm{C}_{2} \mathrm{O}_{4}\right)_{3}\right] \cdot 18$-crown-6 & $P-1$ & $T_{\mathrm{c}}=4.0-4.9 \mathrm{~K}$ & [45] \\
\hline$\beta^{\prime \prime}$-(BEDT-TTF) ${ }_{4}\left[\left(\mathrm{NH}_{4}\right) \mathrm{Cr}\left(\mathrm{C}_{2} \mathrm{O}_{4}\right)_{3}\right]_{2} \cdot\left[\left(\mathrm{NH}_{4}\right)_{2}\right.$ 18-crown-6] $\left(\mathrm{H}_{2} \mathrm{O}\right)_{5}$ & $P-1$ & $T_{\mathrm{MI}}=190 \mathrm{~K}$ & {$[46,47]$} \\
\hline$\beta^{\prime \prime}$-(BEDT-TTF) ${ }_{4}\left[\left(\mathrm{NH}_{4}\right) \mathrm{Ga}\left(\mathrm{C}_{2} \mathrm{O}_{4}\right)_{3}\right]_{2} \cdot\left[\left(\mathrm{NH}_{4}\right)_{2}\right.$ 18-crown-6]($\left(\mathrm{H}_{2} \mathrm{O}\right)_{5}$ & $P-1$ & $T_{\mathrm{Ml}}=240 \mathrm{~K}$ & [47] \\
\hline
\end{tabular}


Table 8 Radical cation-salts of BEDT-TTF with tris(oxalato)metallate(III) and their conducting properties.

\begin{tabular}{|c|c|c|c|}
\hline Formula & $\begin{array}{l}\text { Space } \\
\text { Group }\end{array}$ & $\begin{array}{l}\text { Conducting } \\
\text { Properties }\end{array}$ & Reference \\
\hline$\beta^{\prime}-(\mathrm{BEDT}-\mathrm{TTF})_{5}\left[\mathrm{Fe}\left(\mathrm{C}_{2} \mathrm{O}_{4}\right)_{3}\right] \cdot\left(\mathrm{H}_{2} \mathrm{O}\right)_{2} \cdot \mathrm{CH}_{2} \mathrm{Cl}_{2}$ & $P-1$ & $E_{\mathrm{a}}=30 \mathrm{meV}$ & [48] \\
\hline $\mathrm{a}^{\prime \prime \prime}-(\mathrm{BEDT}-\mathrm{TTF})_{9}\left[\mathrm{Fe}\left(\mathrm{C}_{2} \mathrm{O}_{4}\right)_{3}\right]_{8} \mathrm{Na}_{18}\left(\mathrm{H}_{2} \mathrm{O}\right)_{24}$ & $P-1$ & $E_{\mathrm{a}}=77 \mathrm{meV}$ & [49] \\
\hline $\mathrm{a}^{\prime \prime \prime}-(\mathrm{BEDT}-\mathrm{TTF})_{9}\left[\mathrm{Cr}\left(\mathrm{C}_{2} \mathrm{O}_{4}\right)_{3}\right]_{8} \mathrm{Na}_{18}\left(\mathrm{H}_{2} \mathrm{O}\right)_{24}$ & $P-1$ & $E_{\mathrm{a}}=66 \mathrm{meV}$ & [42] \\
\hline $\mathrm{a}$-(BEDT-TTF) ${ }_{12}\left[\mathrm{Fe}\left(\mathrm{C}_{2} \mathrm{O}_{4}\right)_{3}\right]_{2} \cdot\left(\mathrm{H}_{2} \mathrm{O}\right)_{15}$ & $C 2 / c$ & Semiconductor & [50] \\
\hline $\mathrm{a}$-(BEDT-TTF) ${ }_{12}\left[\mathrm{Fe}\left(\mathrm{C}_{2} \mathrm{O}_{4}\right)_{3}\right]_{2} \cdot\left(\mathrm{H}_{2} \mathrm{O}\right)_{16}$ & $C 2 / c$ & Semiconductor & [50] \\
\hline $\mathrm{a}$-(BEDT-TTF $)_{10}(18 \text {-crown-6) })_{6} \mathrm{~K}_{6}\left[\mathrm{Fe}\left(\mathrm{C}_{2} \mathrm{O}_{4}\right)_{3}\right]_{4}\left(\mathrm{H}_{2} \mathrm{O}\right)_{24}$ & $P 2_{1} / c$ & $E_{\mathrm{a}}=105 \mathrm{meV}$ & [49] \\
\hline$\eta$-(BEDT-TTF) ${ }_{4}\left(\mathrm{H}_{2} \mathrm{O}\right) \mathrm{LiFe}\left(\mathrm{C}_{2} \mathrm{O}_{4}\right)_{3}$ & $P 2_{1} / n$ & $E_{\mathrm{a}}=80 \mathrm{meV}$ & [43] \\
\hline$(\mathrm{BEDT}-\mathrm{TTF})_{2.53}\left[\mathrm{MnRh}\left(\mathrm{C}_{2} \mathrm{O}_{4}\right)_{3}\right] \cdot \mathrm{CH}_{2} \mathrm{Cl}_{2}$ & $P-1$ & Metal > $2 \mathrm{~K}$ & [51] \\
\hline (BEDT-TTF) $)_{x}\left[\mathrm{MnCr}\left(\mathrm{C}_{2} \mathrm{O}_{4}\right)_{3}\right] \cdot \mathrm{CH}_{2} \mathrm{Cl}_{2} \quad x=<3$ & $P-1$ & Metal $>0.3 \mathrm{~K}$ & {$[6,51,52]$} \\
\hline $\mathrm{a}^{\prime \prime}$-(BEDT-TTF) $)_{5}\left[\mathrm{Ga}\left(\mathrm{C}_{2} \mathrm{O}_{4}\right)_{3}\right] \cdot\left(\mathrm{H}_{2} \mathrm{O}\right)_{3.4} \cdot(\mathrm{EtOH})_{0.6}$ & Pbca & $E_{\mathrm{a}}=71 \mathrm{meV}$ & [29] \\
\hline
\end{tabular}


Table 9 Radical cation-salts of BEDT-TTF with tris(oxalato)germanate(IV) and their conducting properties. $\mathrm{Ph}=$ Phenyl.

\begin{tabular}{|l|l|l|l|}
\hline Formula & $\begin{array}{l}\text { Space } \\
\text { Group }\end{array}$ & Conducting Properties & Reference \\
\hline (BEDT-TTF $)_{2}\left[\mathrm{Ge}\left(\mathrm{C}_{2} \mathrm{O}_{4}\right)_{3}\right] \cdot \mathrm{PhCN}$ & $\mathrm{P} 2_{1} / \mathrm{c}$ & $E_{\mathrm{a}}=127 \mathrm{meV}$ & {$[53]$} \\
\hline$(\mathrm{BEDT}-\mathrm{TTF})_{5}\left[\mathrm{Ge}\left(\mathrm{C}_{2} \mathrm{O}_{4}\right)_{3}\right]_{2}$ & $\mathrm{C} 2$ & $E_{\mathrm{a}}=225 \mathrm{meV}$ & {$[54]$} \\
\hline$(\mathrm{BEDT}-\mathrm{TTF})_{7}\left[\mathrm{Ge}\left(\mathrm{C}_{2} \mathrm{O}_{4}\right)_{3}\right]_{2}\left(\mathrm{CH}_{2} \mathrm{Cl}_{2}\right)_{0.87}\left(\mathrm{H}_{2} \mathrm{O}\right)_{0.09}$ & $\mathrm{C} 2 / \mathrm{c}$ & $E_{\mathrm{a}}=172 \mathrm{meV}$ & {$[54]$} \\
\hline$(\mathrm{BEDT}-\mathrm{TTTF})_{4} \mathrm{Ge}\left(\mathrm{C}_{2} \mathrm{O}_{4}\right)_{3} \cdot\left(\mathrm{CH}_{2} \mathrm{Cl}_{2}\right)_{0.50}$ & $\mathrm{P} 2_{1} / \mathrm{c}$ & $E_{\mathrm{a}}=224 \mathrm{meV}$ & {$[55]$} \\
\hline
\end{tabular}




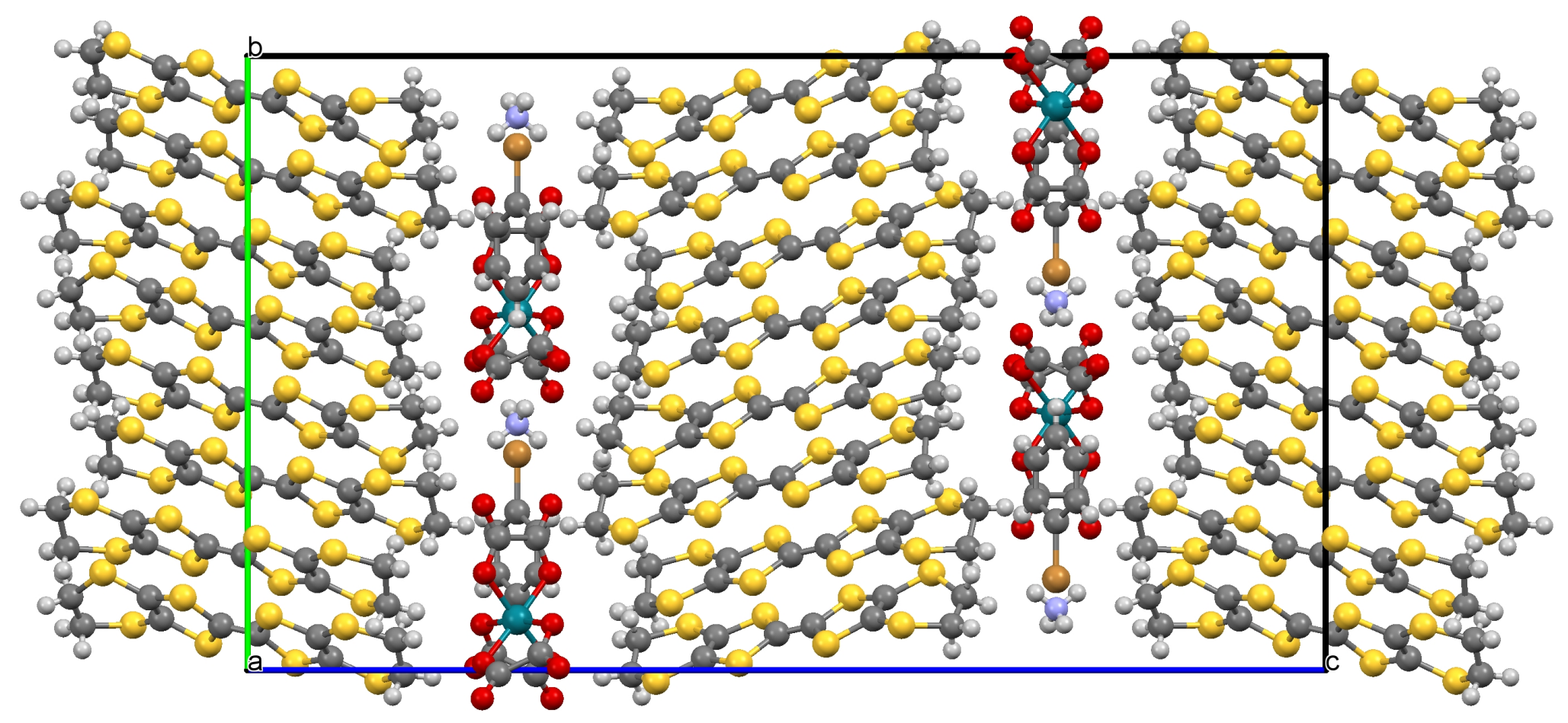




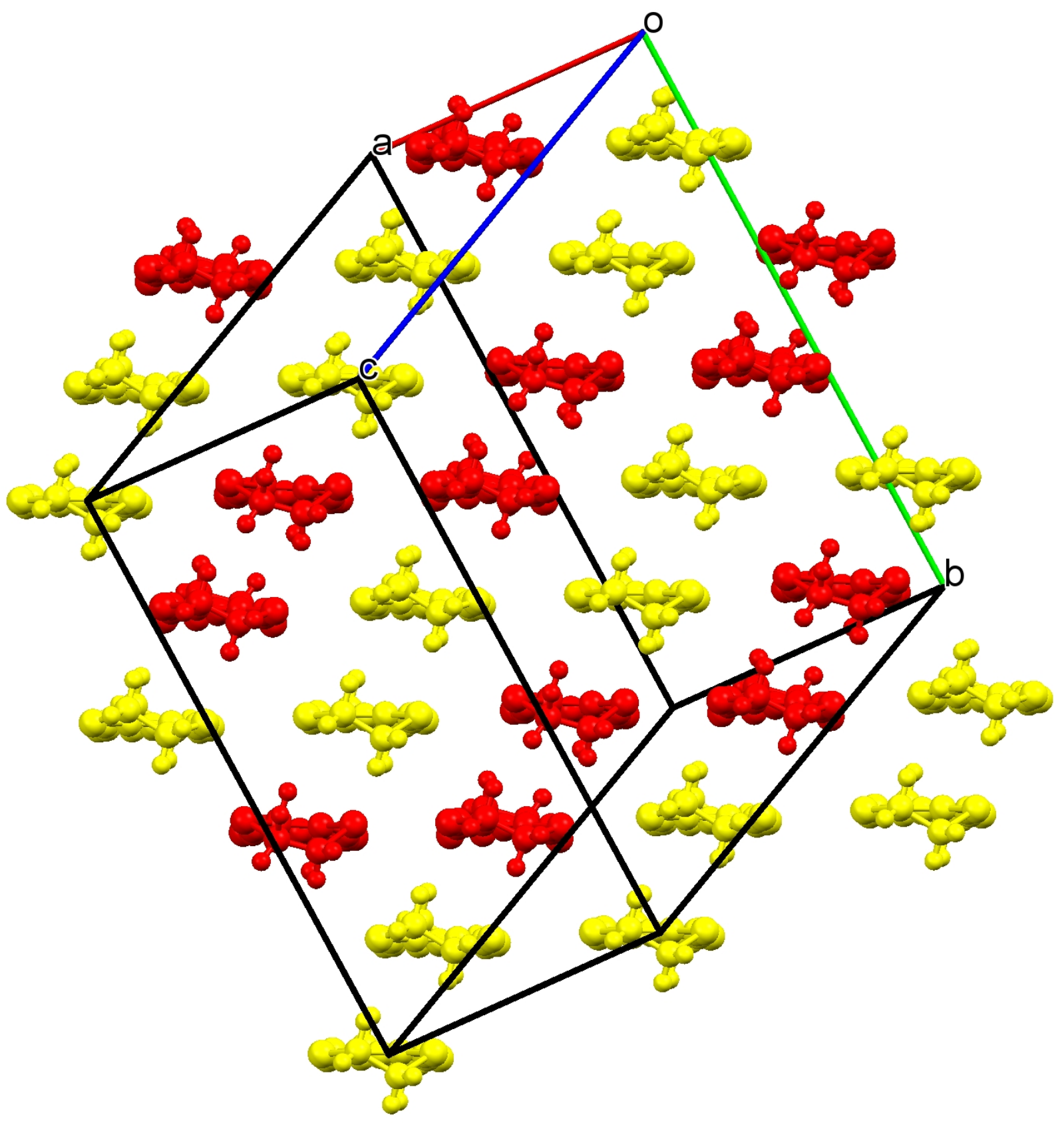




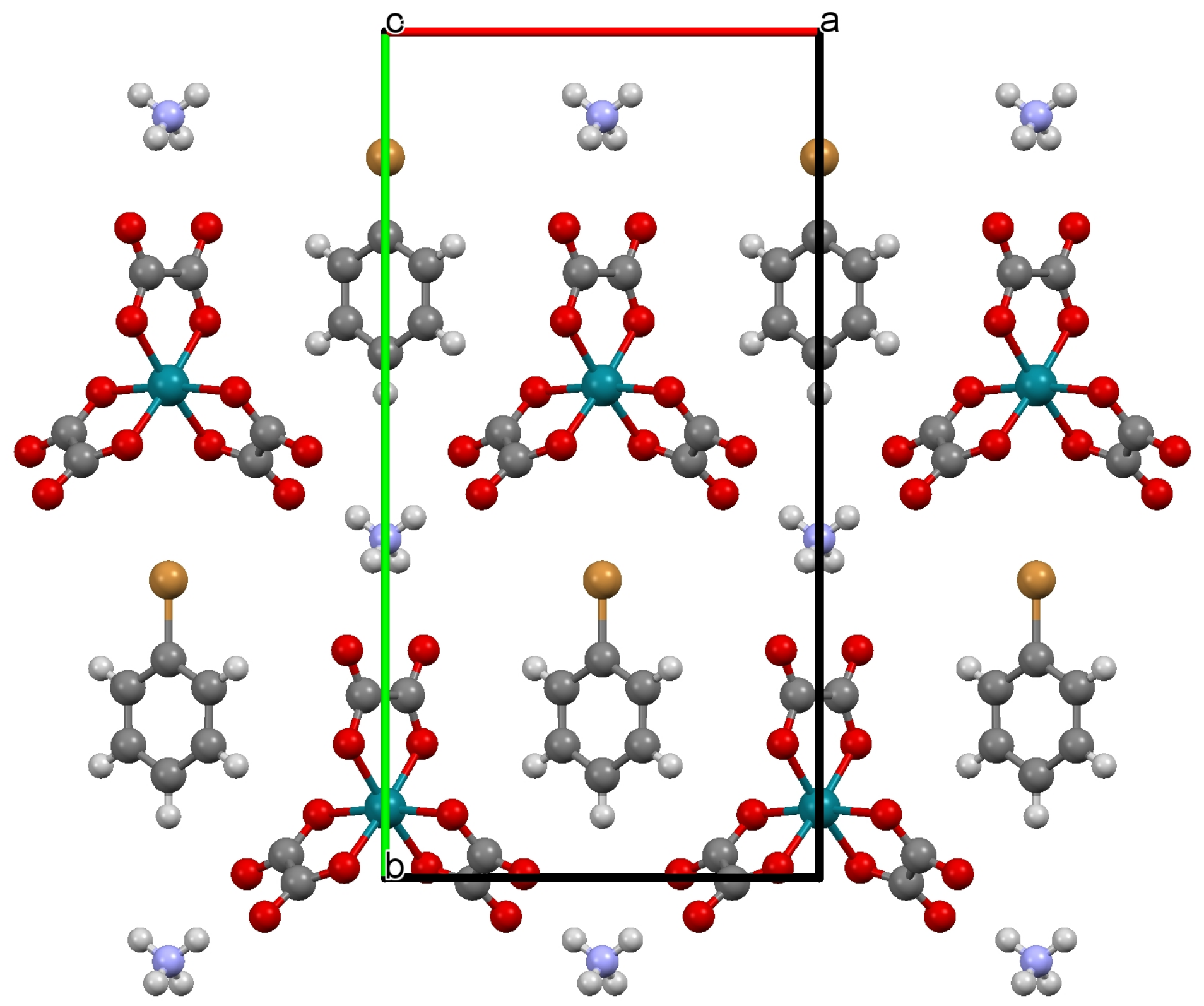




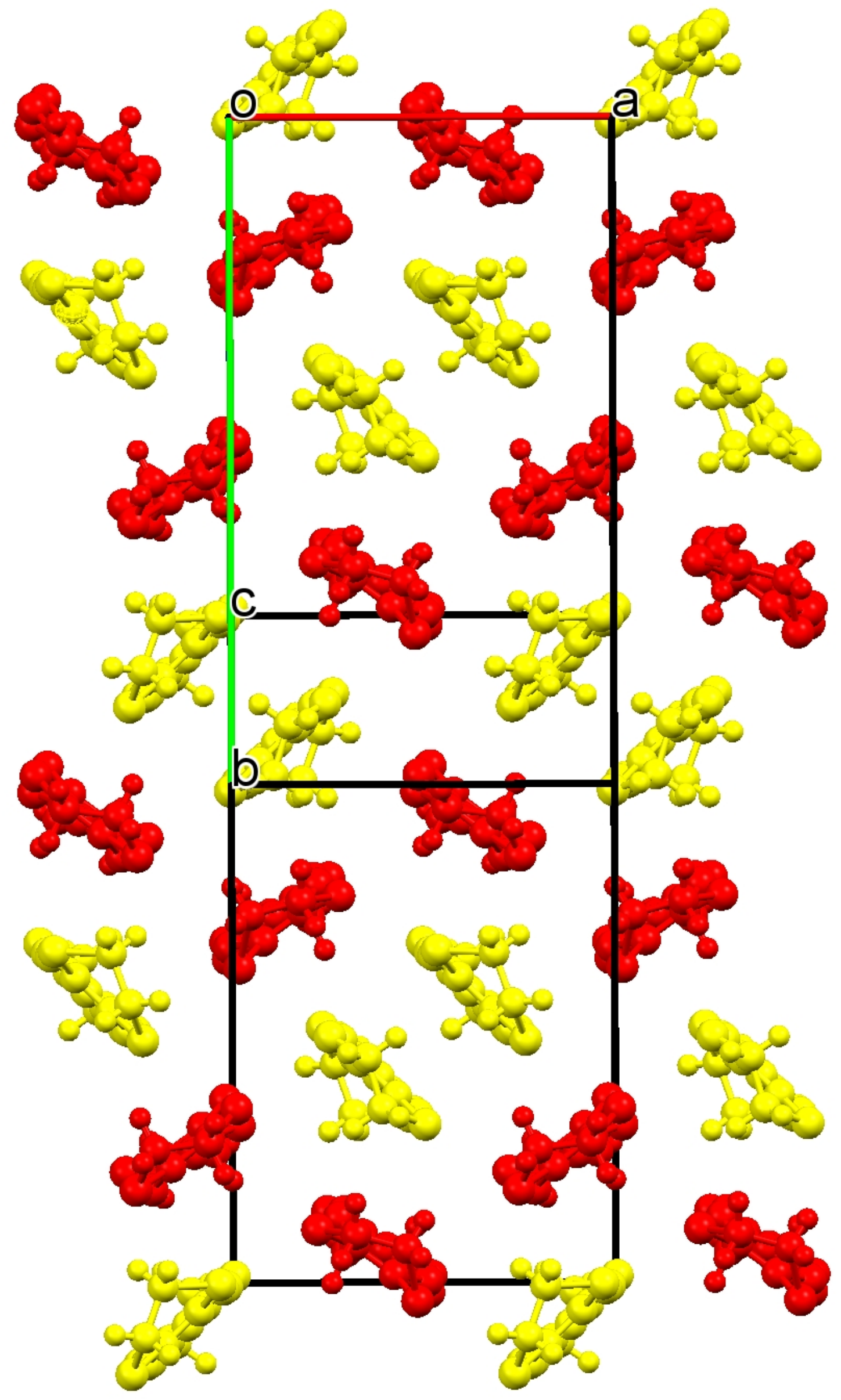




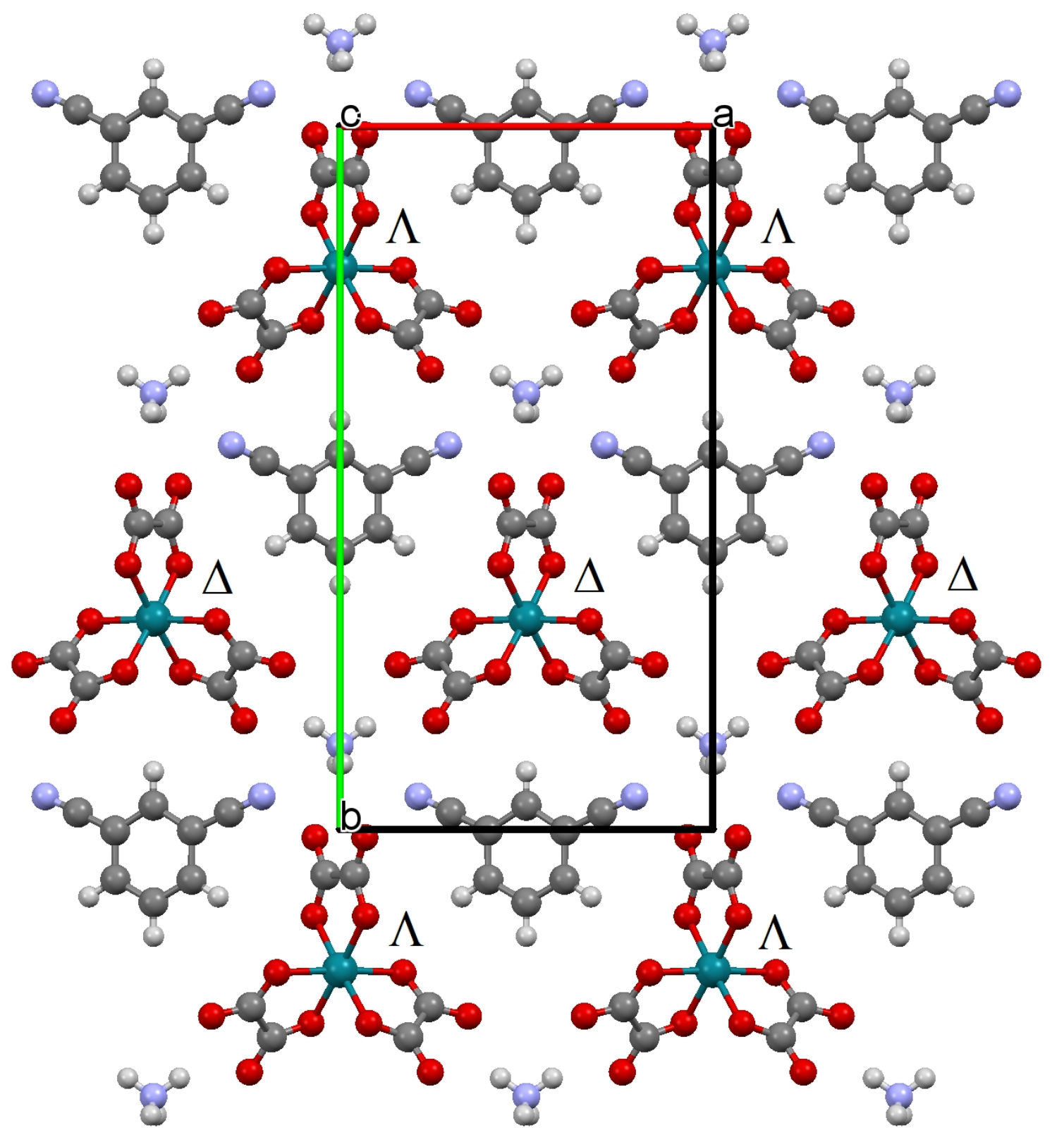




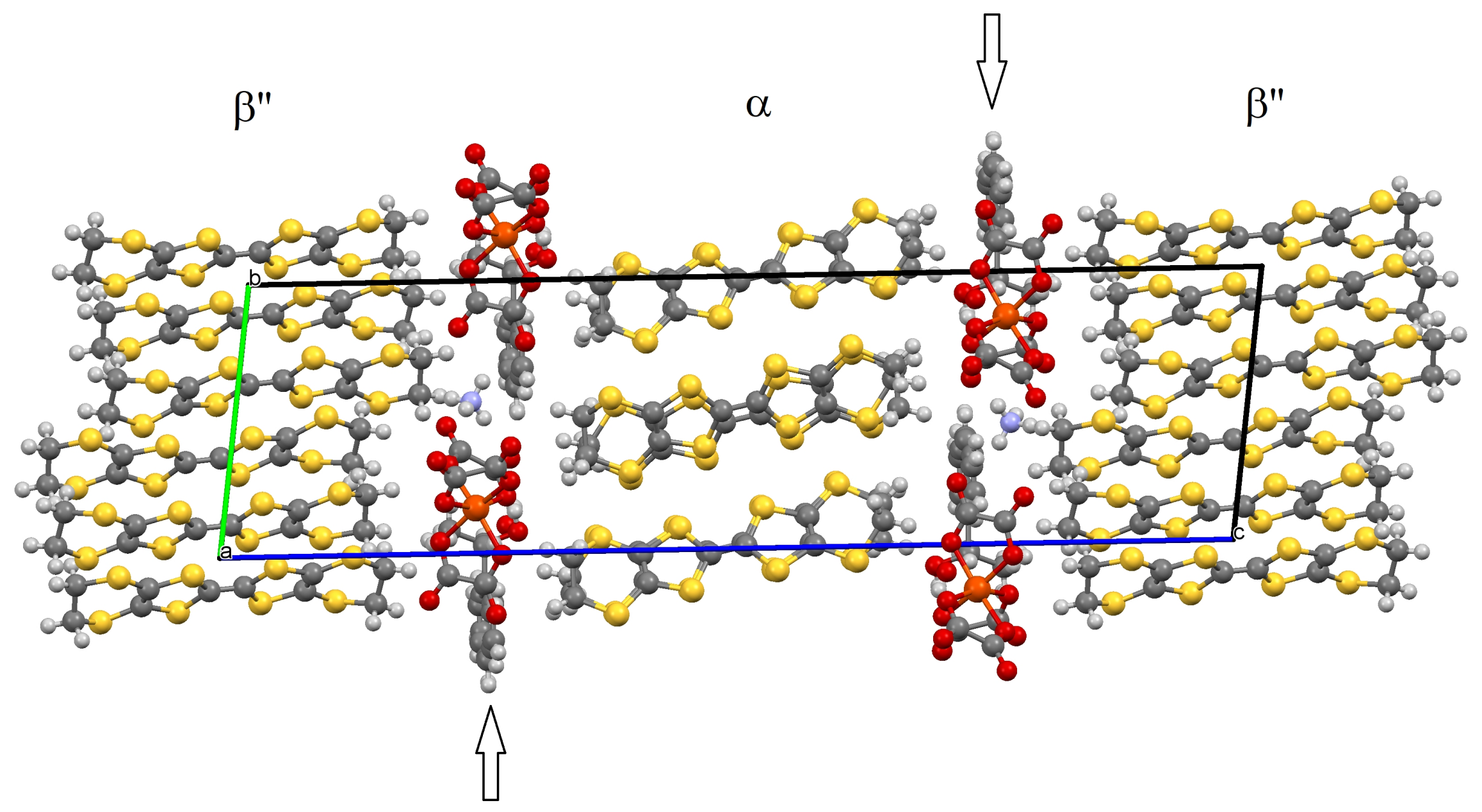




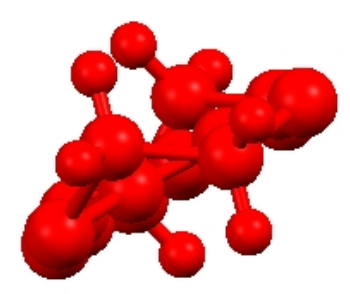

.

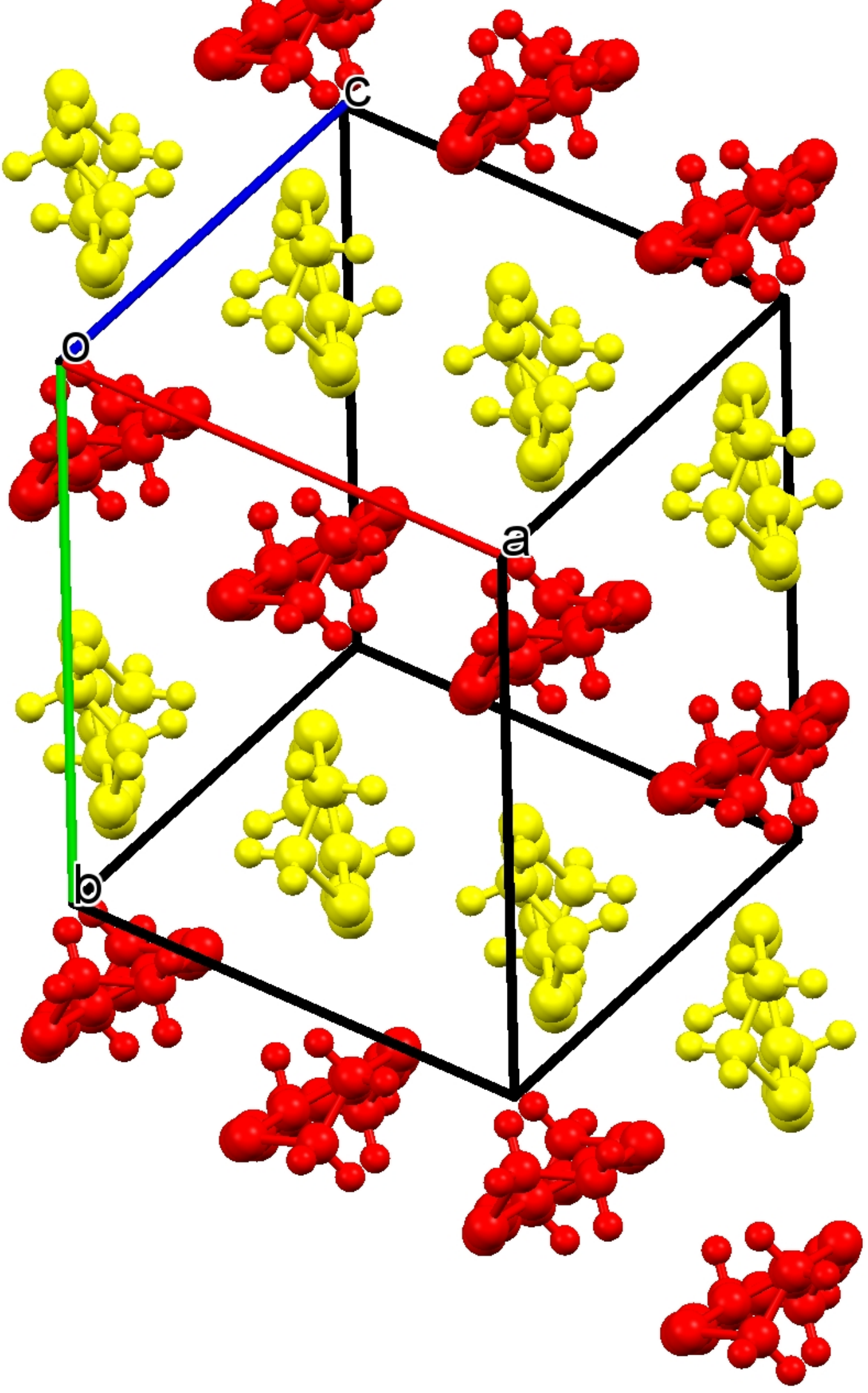


(a)

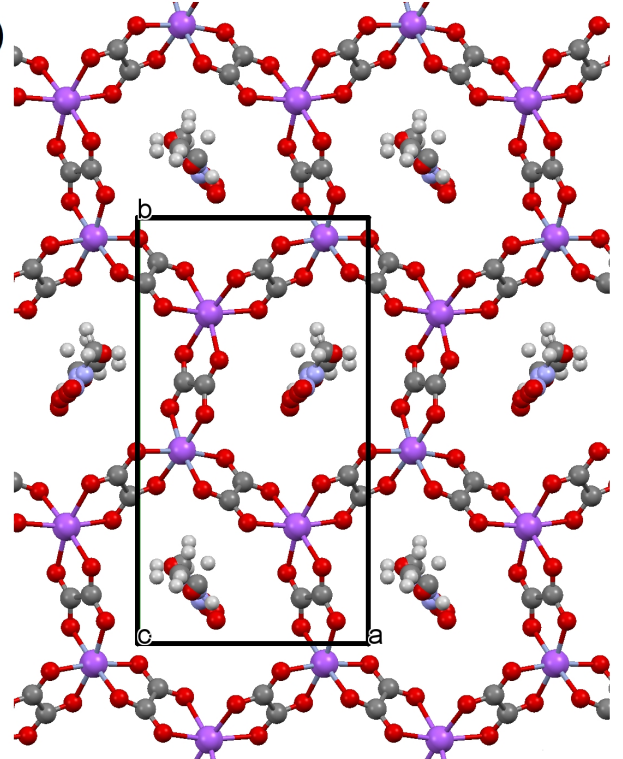

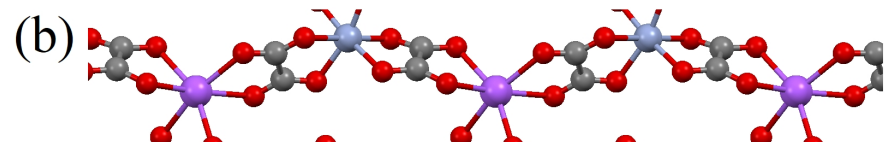

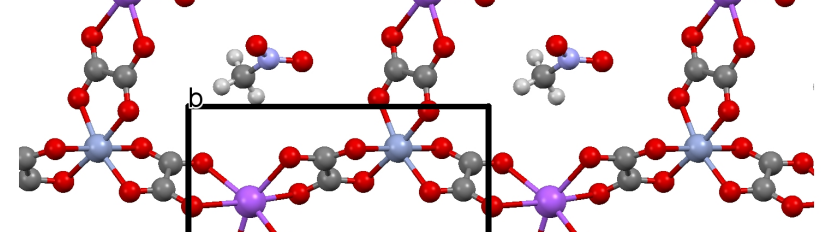

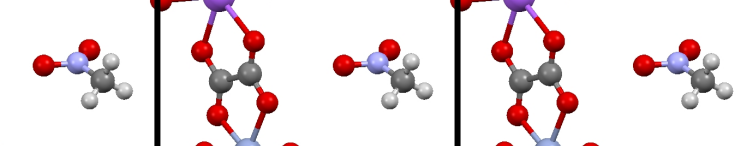
rea derara drodba ag \&ो का की की o. (c)

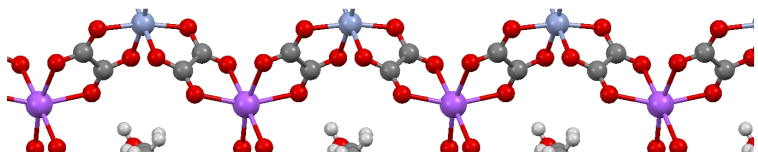

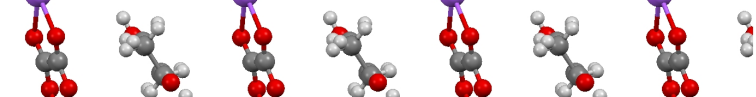
50. of of of jo \& $\%$ \& $\%$ \&

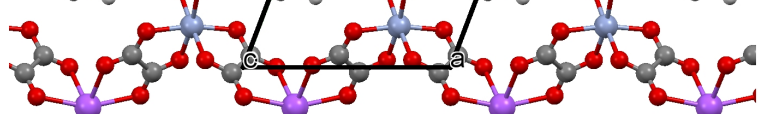

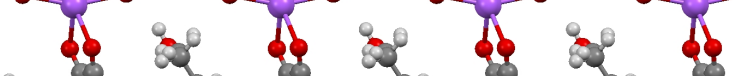
$\circ$ \&

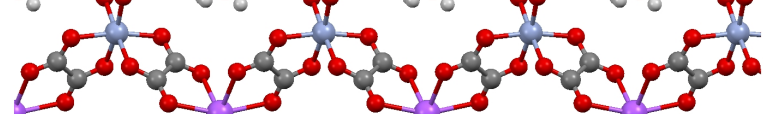


(a) $x+5$ \& $\div$ cos 3 o (2)

(b) वर्य

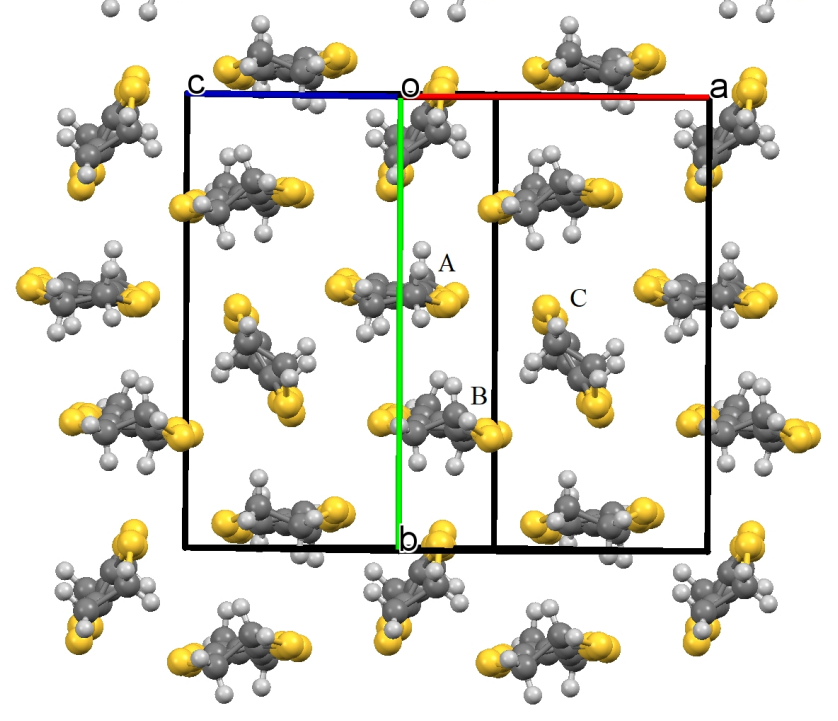

(c) G T. 选

T 选

(d)

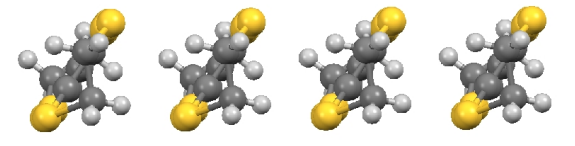

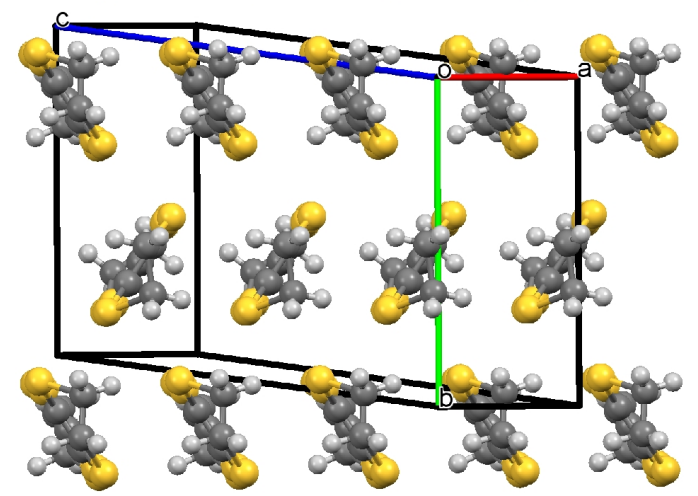




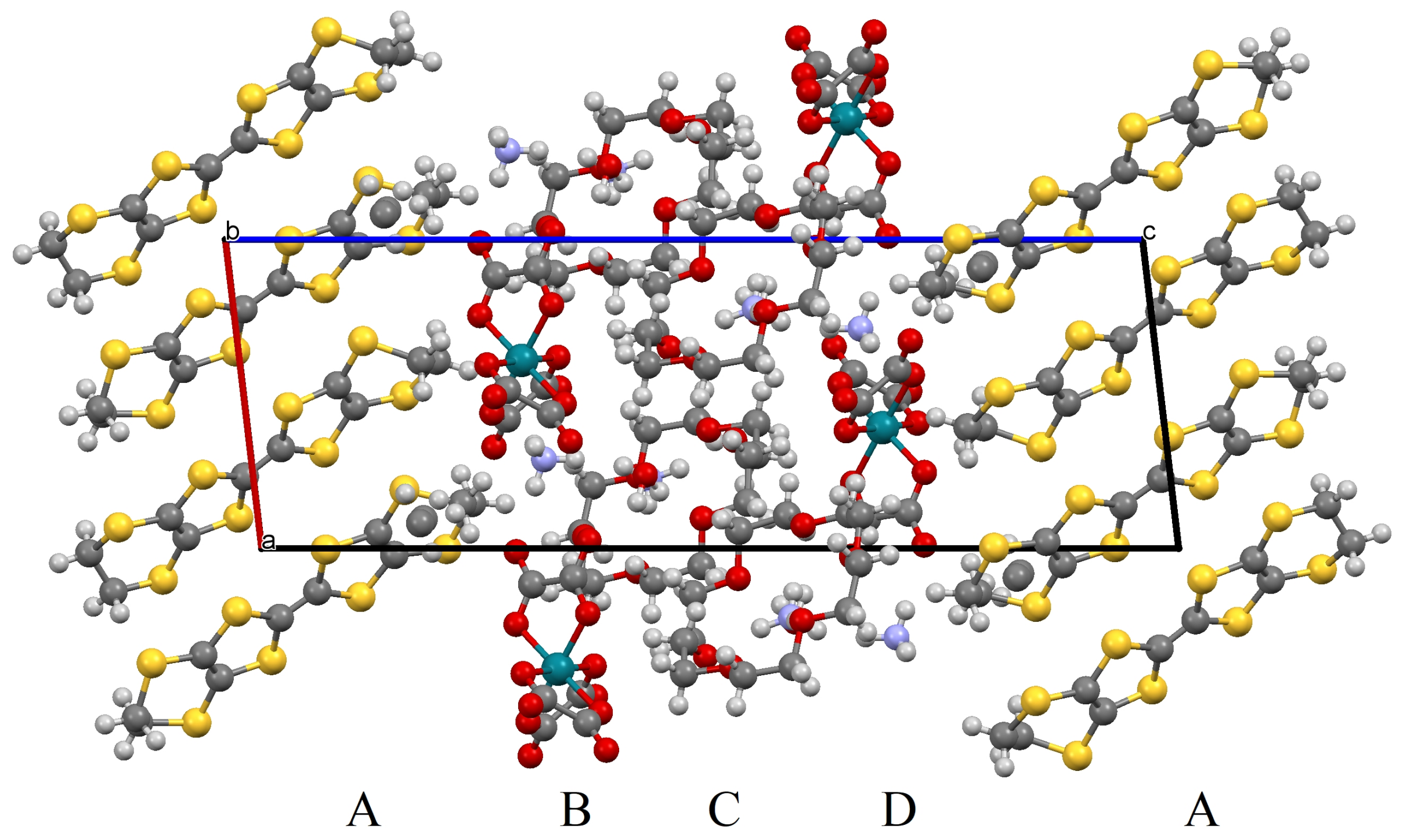




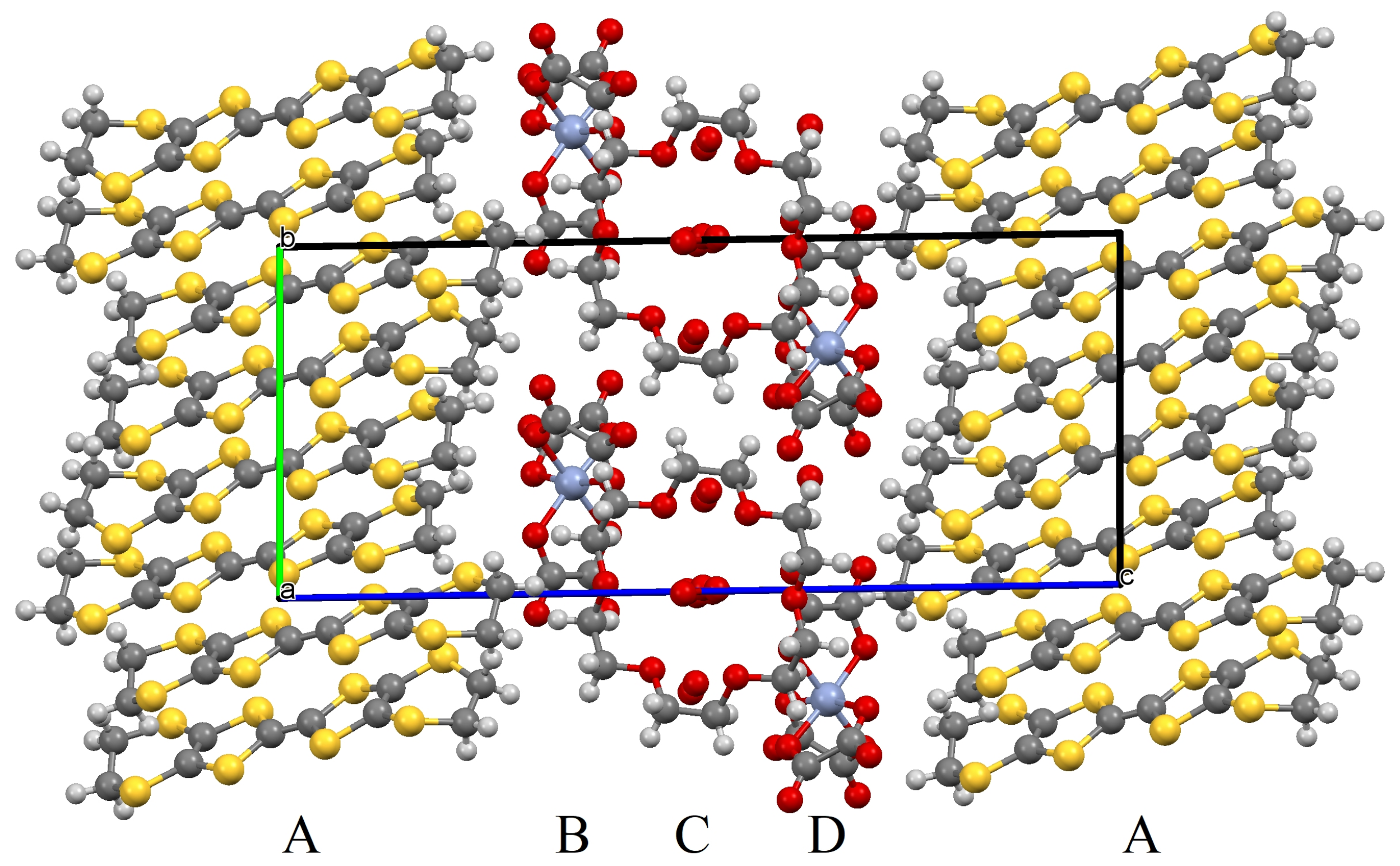


(a)
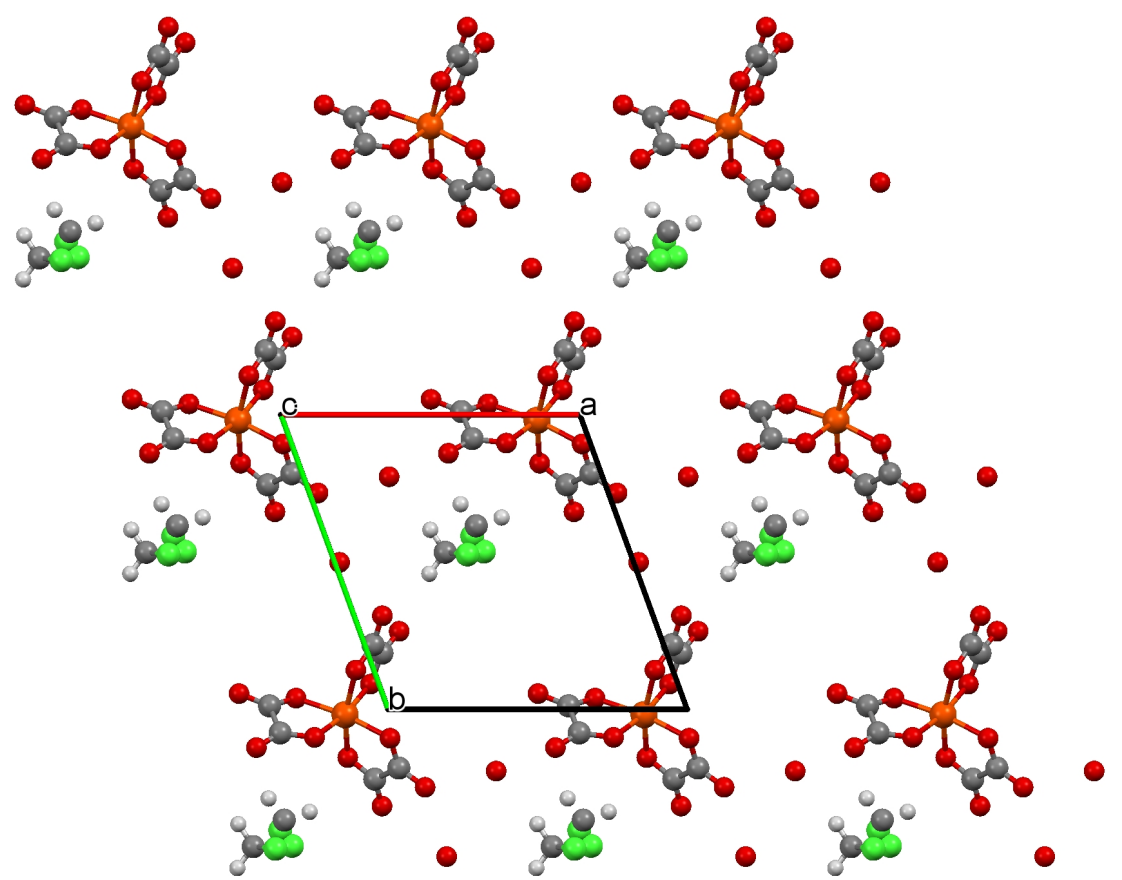

(b)

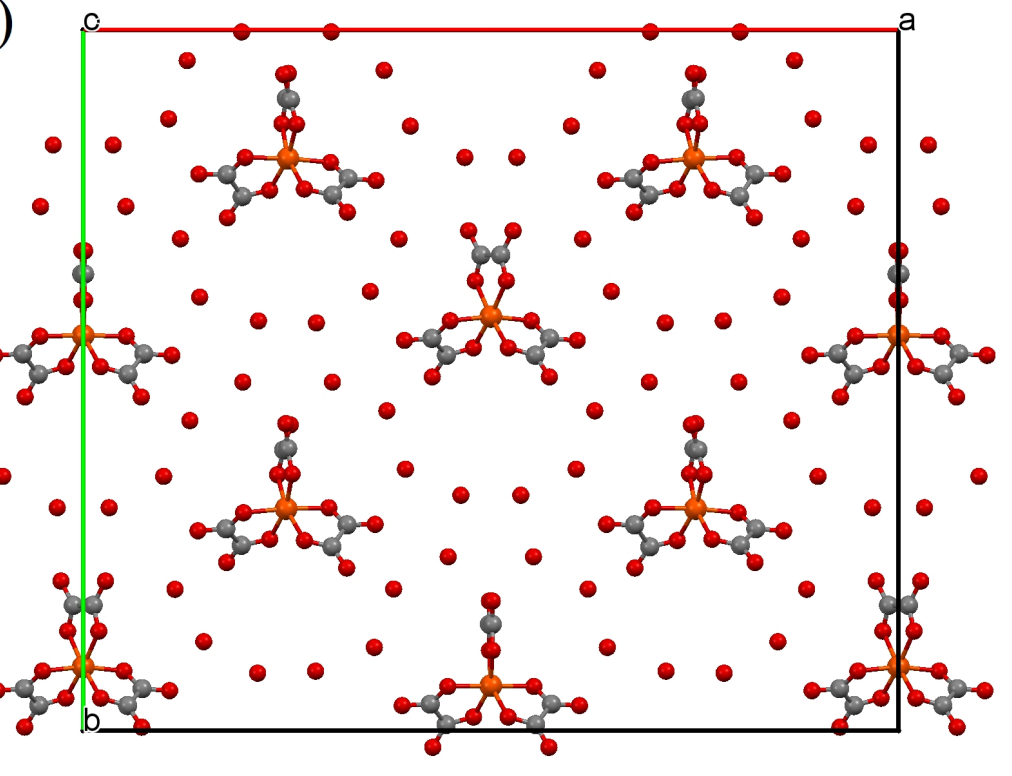


(a)

So क्ष
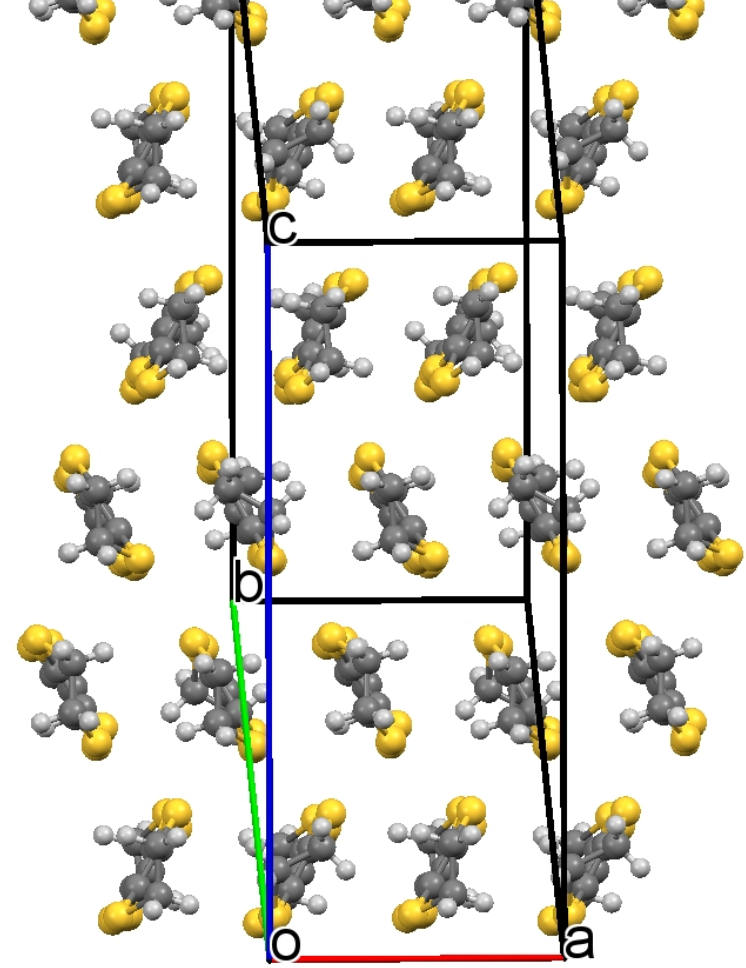

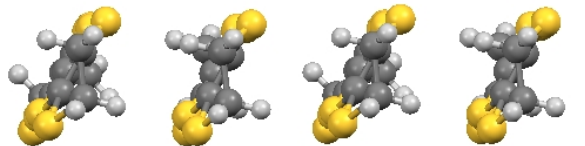

(b)
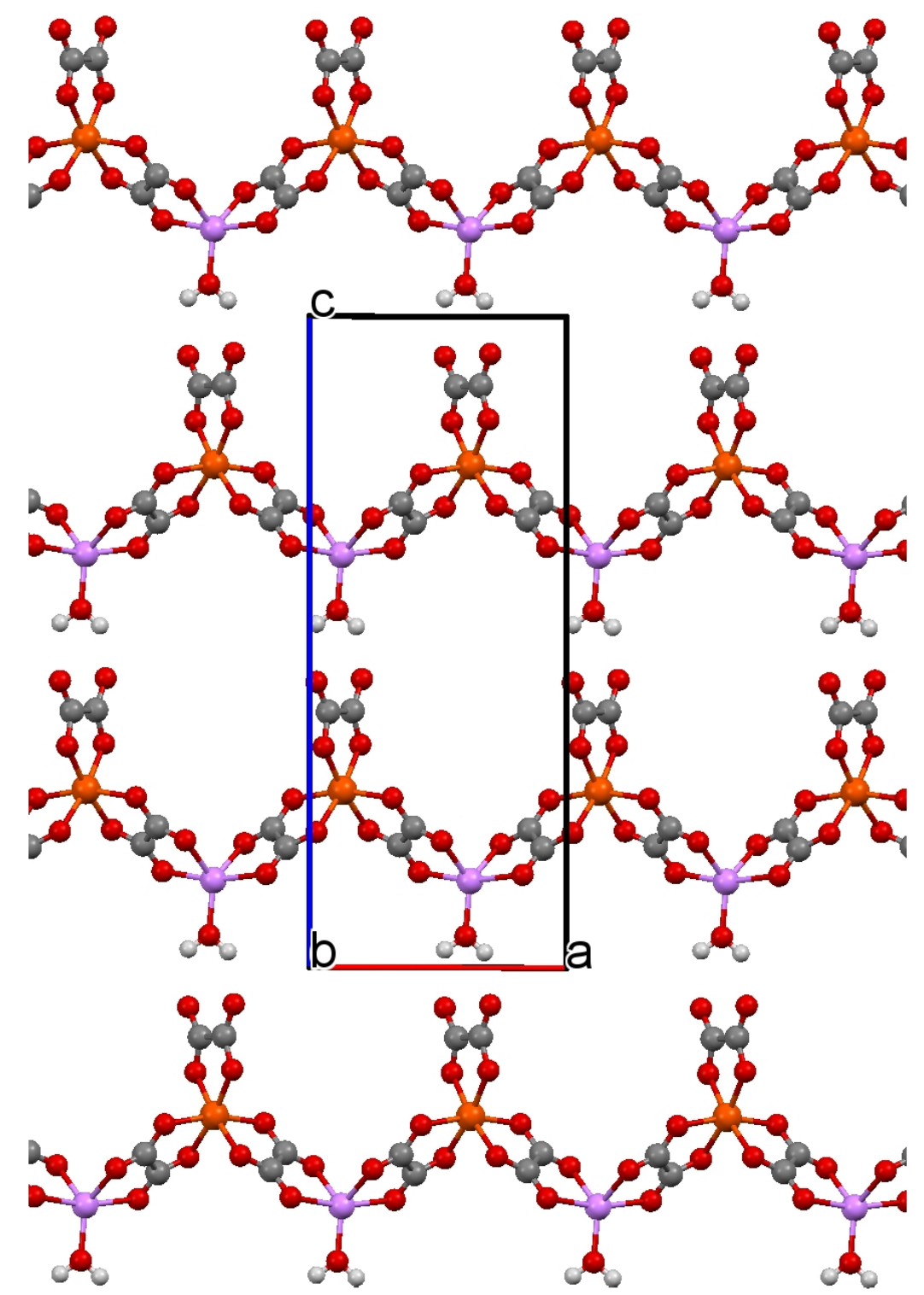


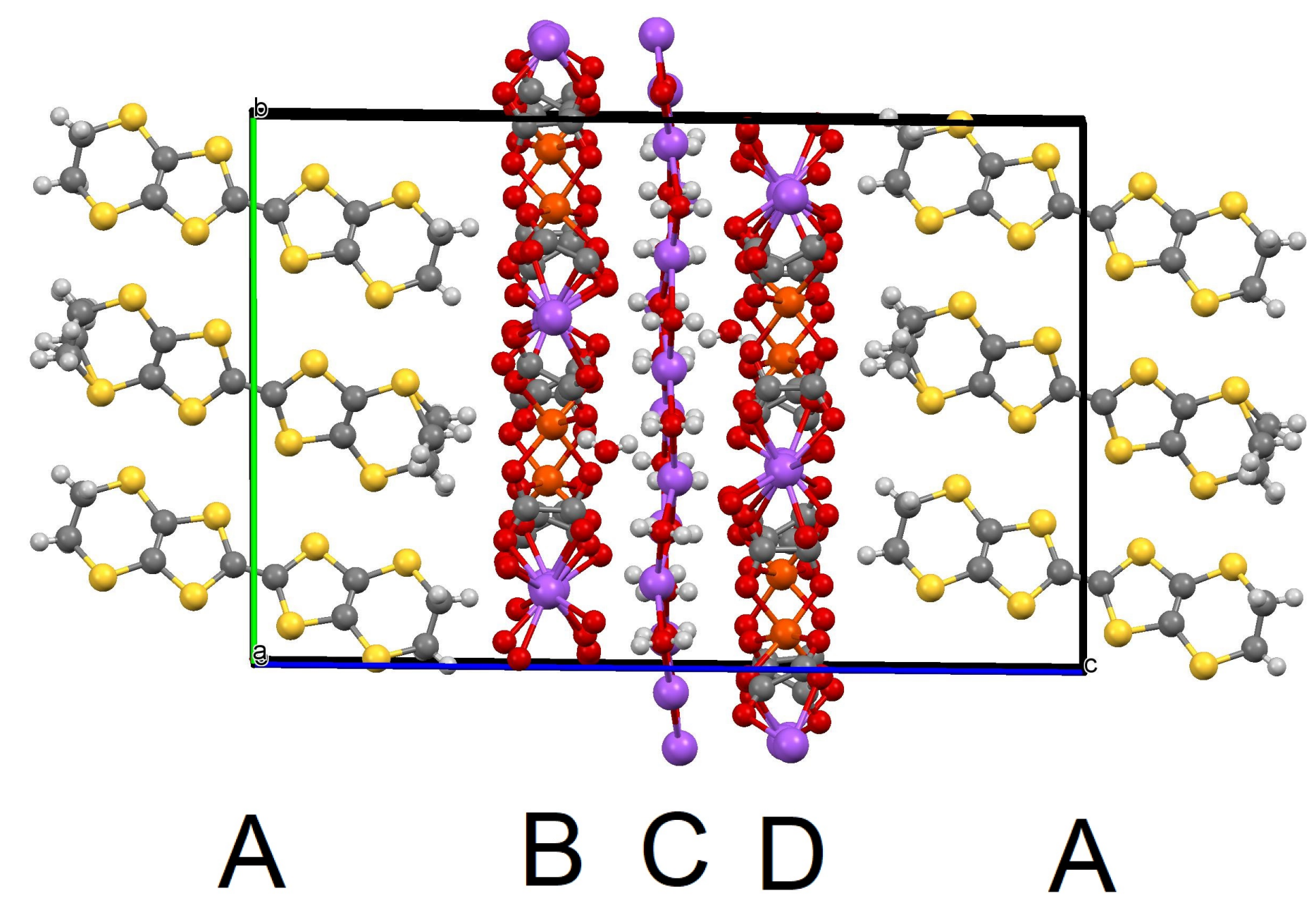




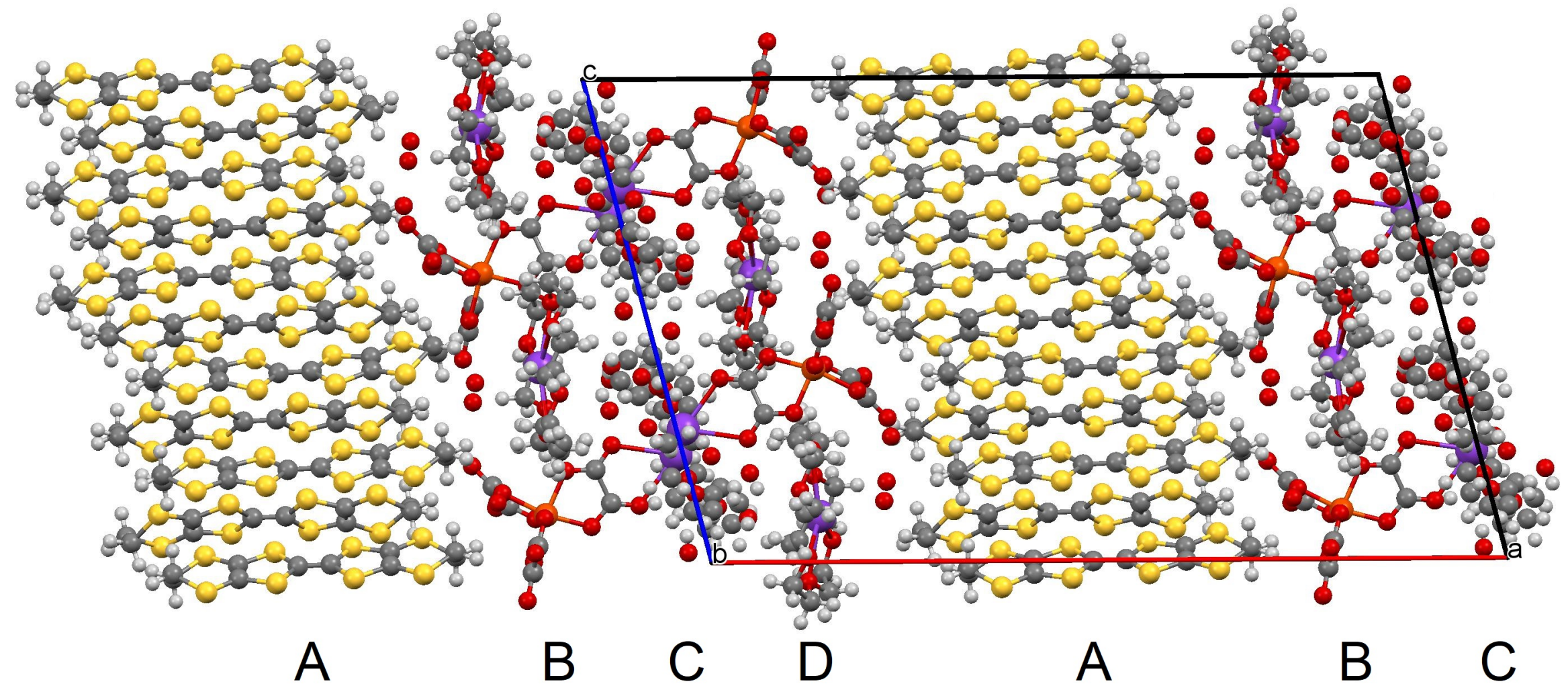


(a)

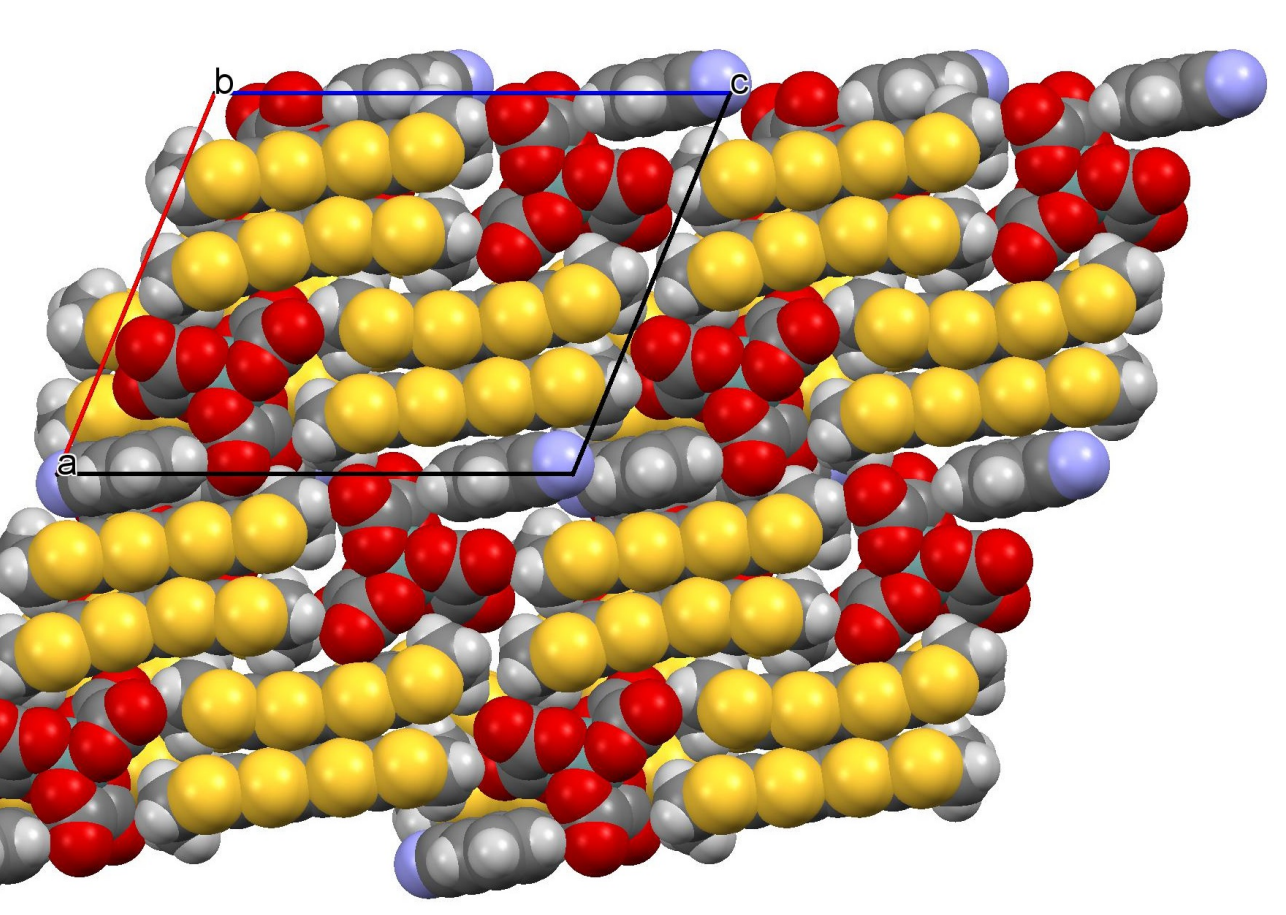

(b)

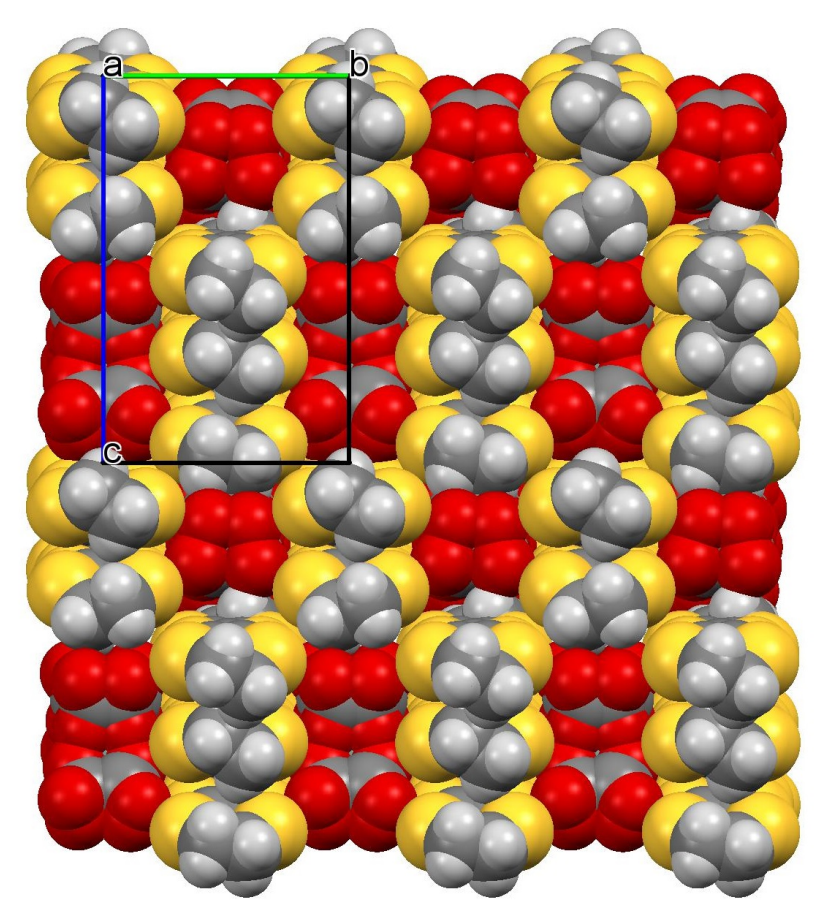




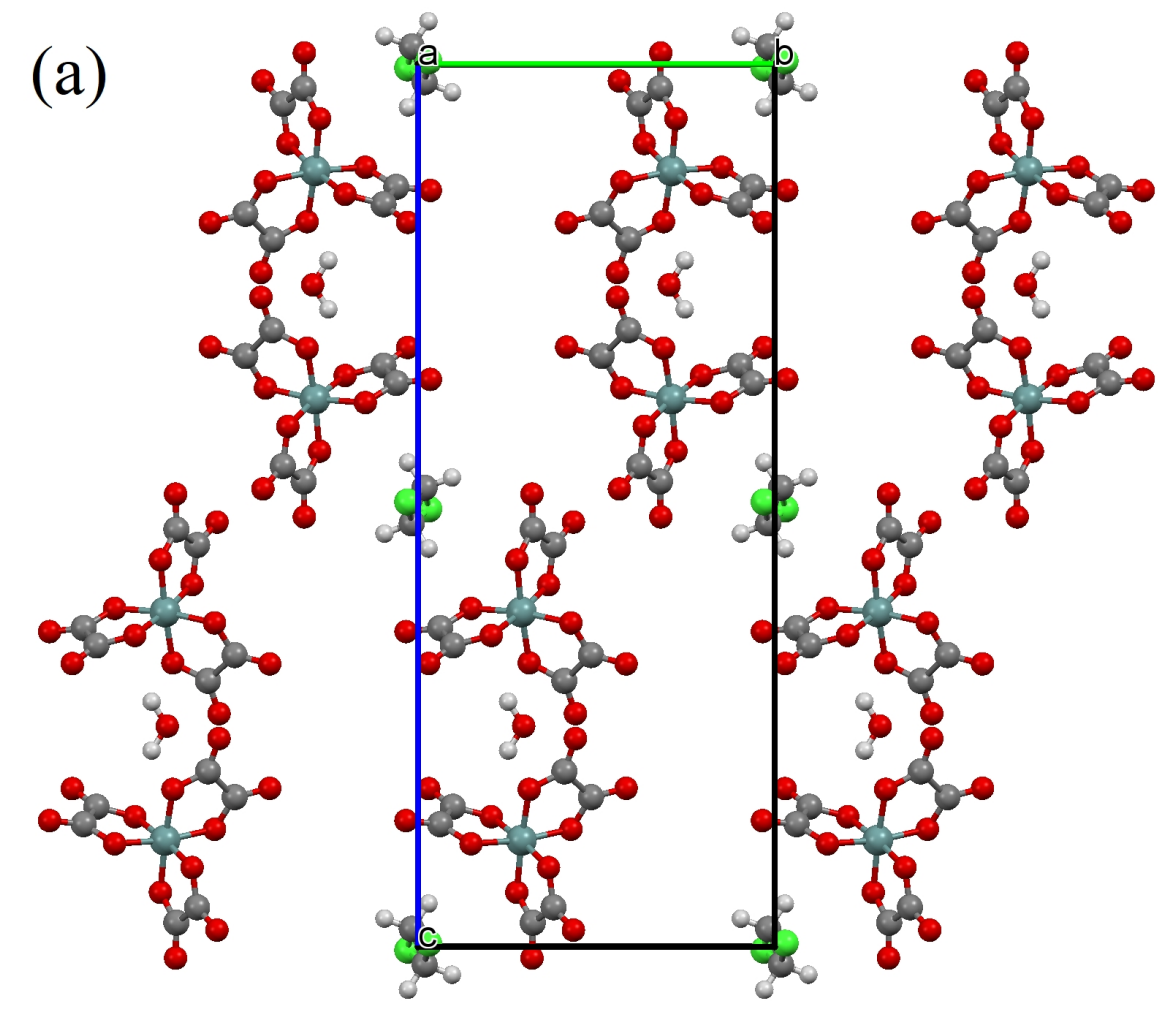

(b)

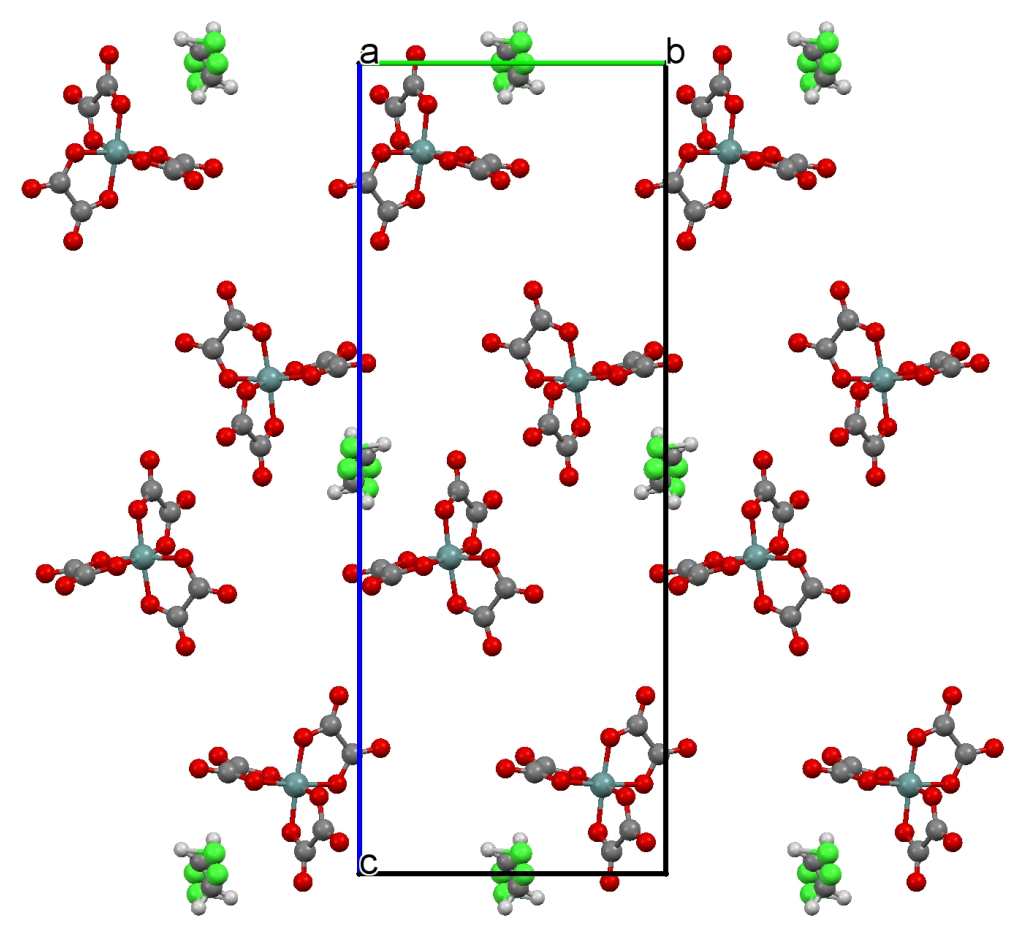




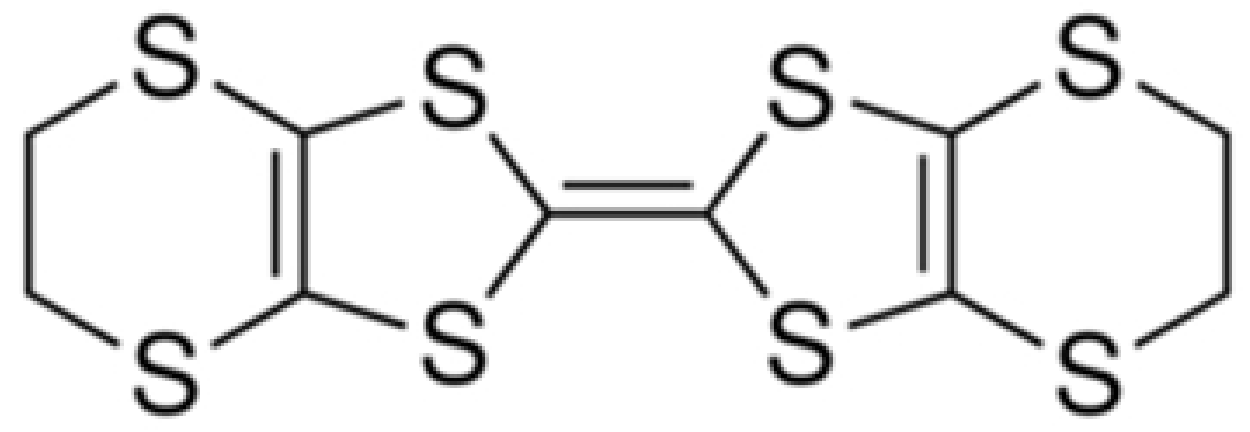




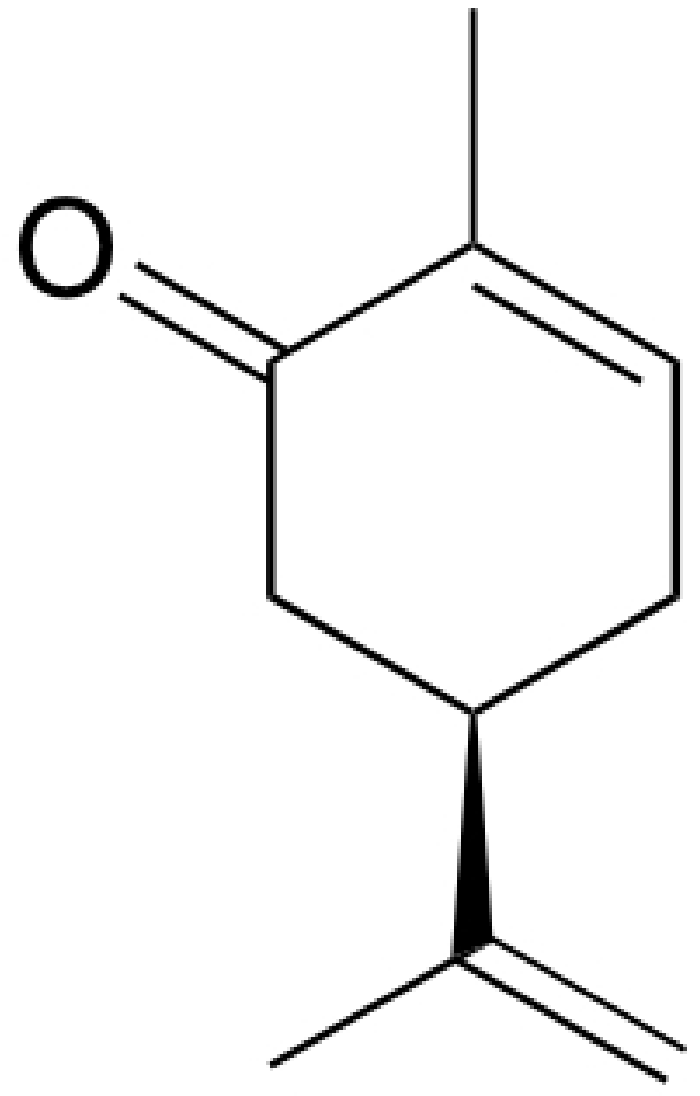

